\title{
Methods of Modulation for Current-Source Single-Phase Isolated Matrix Converter in a Grid-Connected Battery Application
}

\author{
Goh Teck Chiang *(D) and Takahide Sugiyama \\ Toyota Central R\&D Labs Inc., Nagakute City 480-1192, Japan; t-sugiyama@mosk.tytlabs.co.jp \\ * Correspondence: tcgoh@mosk.tytlabs.co.jp
}

Received: 29 May 2020; Accepted: 21 July 2020; Published: 27 July 2020

check for updates

\begin{abstract}
This paper discusses three methods of modulation for a single-phase isolated matrix converter. The matrix converter is combined with a transformer integration to perform power decoupling control in order to reduce the number of component and capacitor volumes. Due to the reason of (i) Alternating current (AC/AC) direct conversion and (ii) transformer integration, obtaining a clean sinusoidal grid current waveform in the modulation of matrix converter (MC) is important. Three methods of modulation are compared in terms of control complexity, quality waveform, and inductive-capacitive-inductive (LCL) filter sizing. The principal control of each method is described. Finally, a prototype was tested to verify the validity and the effectiveness of grid current control and power decoupling in the spoken circuit structure.
\end{abstract}

Keywords: AC/AC conversion; decoupling control; modulation

\section{Introduction}

The rapidly expanding growth of battery storage system (BSS) has urged high demands for a single-phase power converter. Figure 1a shows the applications such as home energy management system (HEMS), uninterruptible power supply (UPS), and small-scale datacenter, which uses a single-phase power converter as an interface between BSS and grid (AC 80-240 V 50/60 Hz). These applications require isolation and typically rate from $1-3 \mathrm{~kW}$ with a high voltage battery (100-300 V). As the price of battery is expected to reach a new low in the near future, a low cost and small size single-phase power converter is highly demanded.

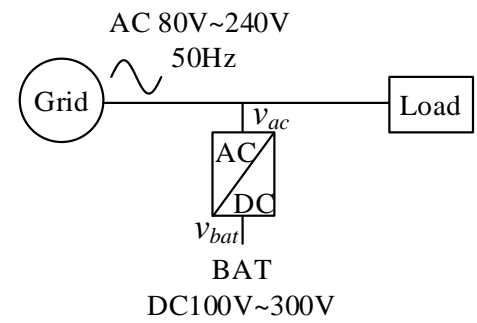

(a)

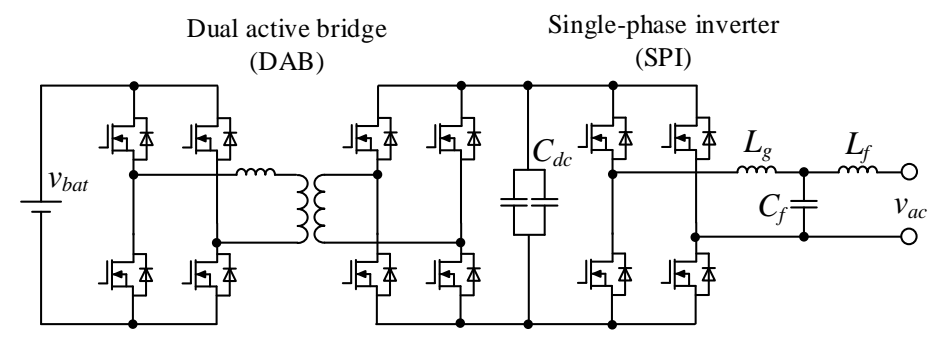

(b)

Figure 1. (a) Single-phase power converter for a grid-connected battery application. (b) Conventional circuit structure consists of a dual-active bridge (DAB) and a single-phase inverter (SPI).

Figure $1 \mathrm{~b}$ shows the conventional circuit for a single-phase power converter. The circuit is composed of a dual-active bridge (DAB), a single-phase inverter (SPI), and an LCL filter [1,2]. The size reduction of a single-phase power converter is challenging because of using many passive components. 
Several studies have focused on reducing the size of inductive component such as inductor and transformer by using a high frequency technique [3-5]. However, the major size of the converter is occupied by the capacitors $C_{d c}$ that are used to absorb the single-phase power fluctuation. Due to the reason of current limitation in the electrolytic capacitor, capacitors are connected in parallel to form a big capacitor bank in order to absorb the single-phase power fluctuation.

The matrix converter (MC) shows a promising solution for size reduction because the capacitor can be removed [6,7]. Hence, MC can convert high frequency transformer voltage (i.e., $50 \mathrm{kHz}$ ) to low frequency voltage (i.e., $50 \mathrm{~Hz}$ ), at the same time controlling the current flow bidirectional. However, for a single-phase application, a low frequency current that contains twice of the grid frequency occurrs in the battery side due to the direct AC/AC conversion. Depending on the type of battery, such as lithium battery, the single-phase fluctuation in the battery needs to be eliminated in order to protect the battery from overvoltage.

Single-phase active power decoupling techniques have been discussed and reported for compensating the single-phase power fluctuation [8,9]. A power decoupling circuit can be considered to add between the battery and full-bridge inverter (FBI) in order to compensate the single-phase low frequency current. Figure 2 shows a conventional circuit structure that consists of a power decoupling circuit, a FBI, and a MC. The power decoupling circuit consists of an inductor $L_{b}$, a capacitor $C_{b}$, a diode, and two switching devices. The single-phase power fluctuation is compensated by charging and discharging the capacitor $C_{b}$ according to the grid phase angle. As a result, the single-phase power fluctuation can be eliminated with a smaller capacitor than the conventional capacitor bank.
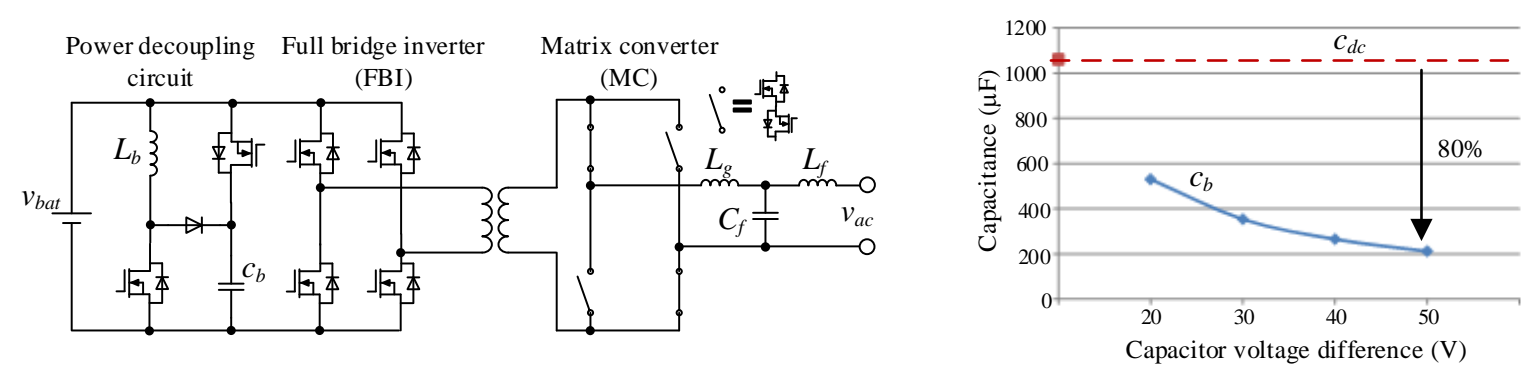

Figure 2. Circuit structure consists of a power decoupling circuit, a full-bridge inverter (FBI), and a matrix converter $(\mathrm{MC})$.

The required capacitance in a single-phase converter can be defined by Equation (1).

$$
c_{b} \geq \frac{p_{c a p}}{2 \times \pi \times 2 \times f_{g} \times \Delta v_{c b} \times v_{c b}} ; \Delta v_{c b}=v_{c b m a x}-v_{c b m i n}
$$

where $v_{c b}$ is the average battery voltage, $\Delta v_{c b}$ is the capacitor voltage difference, and $f_{g}$ is grid frequency. Figure 2 shows that a $1 \mathrm{~kW}$ calculation (capacitor power $\left(p_{c a p}\right)$ is half of the rated power), by using the power decoupling control to increase the capacitor voltage difference $\Delta v_{c b}$ to $50 \mathrm{~V}$, the required capacitance can be reduced by $80 \%$ comparing that to the conventional circuit at the same rated power.

However, the major drawback is that this circuit requires extra switching devices and passive component. Here, an integration technique that utilized the center-tapped of a transformer has been discussed, as shown in Figure $3[10,11]$. The center-tapped of the transformer is utilized by connecting the passive components $\left(L_{b}\right.$ and $C_{b}$ ) in order to perform the power decoupling control. Then, the FBI controls the high frequency transformer voltage and the capacitor voltage at the same time, therefore the switching devices in the power decoupling circuit can be reduced.

Without the transformer integration, the power decoupling circuit can be individually controlled and the method of modulation for the matrix converter is rather simple. Literature reviews [12-14] have demonstrated several valid modulations for the $\mathrm{MC}$, where a good quality waveform can be obtained without the need for concern for the power decoupling. However, when the transformer 
integration is applied with MC, the modulation for MC has to be changed in order to synchronize with the FBI to obtain a proper voltage period. The failure of obtaining a clean sinusoidal waveform can distort the battery current inherently, because this capacitor cannot absorb the current fluctuation.

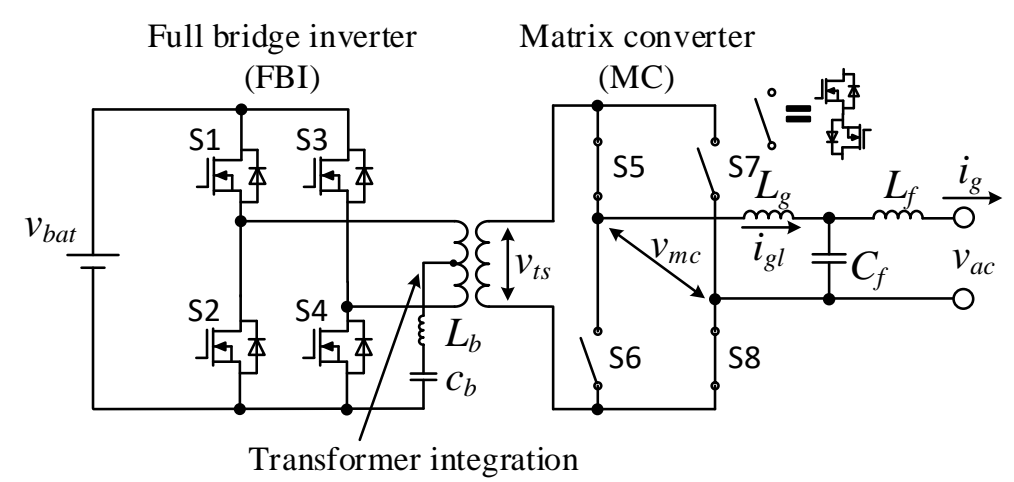

Figure 3. Circuit structure consists of a full-bridge inverter (FBI) with a transformer integration decoupling control and a matrix converter (MC).

This paper discusses three methods of modulation for the MC that is applied with the transformer integration. The first conventional method is a carrier comparison with a D-FF and the second conventional method is a delta-sigma conversion based on pulse density modulation (PDM) which have been addressed in [15-17]. This paper introduces a third method which is a carrier comparison with a zero-vector commutation, and further discusses the difference of each method. The details of each method is described individually. Then, the comparisons among these methods in term of (i) control complexity, (ii) waveform quality, and (iii) LCL sizing are discussed. Then, the validity of the modulation along with comparison results is shown. Finally, a $1 \mathrm{~kW}$ prototype was tested to show the validity of the power decoupling with a MC.

\section{Control Scheme}

\subsection{System Control}

The system control block diagram is shown in Figure 4. The control is divided into two parts: (i) Voltage and current closed-loop controls in FBI and (ii) grid voltage and current with a phase locked loop (PLL) in MC. The FBI is performed as a voltage source to control the high frequency transformer voltage $v_{t s}$ and capacitor voltage $v_{c b}$ at the same time. Then, the high frequency transformer voltage is fed into the $\mathrm{MC}$, and therefore $\mathrm{MC}$ is performed as a current source converter to control the grid current.

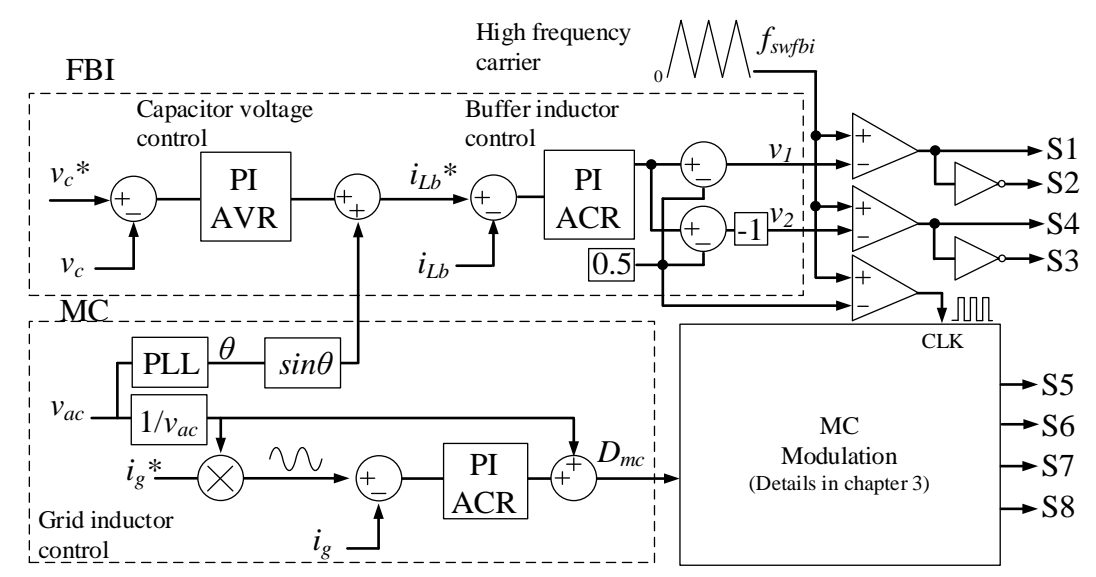

Figure 4. System control block diagram, full-bridge inverter (FBI) controls the voltage level and matrix converter $(\mathrm{MC})$ controls the current for the single-phase power converter. 
In FBI, a low time response of automatic voltage regulator (AVR) is applied to control the capacitor voltage proportionally to half of the battery voltage. Then, the grid phase angle which is calculated from the PLL in the grid control is added to control the phase angle of the inductor current. Then, a high time response current control (automatic current regulator ACR) is applied into the inductor current control. Note that the input of phase angle in the FBI control is also used to enable or disable the power decoupling control (where 0 is disabled).

Since the MC is a current source controller, a normalized grid voltage command is feed-forwarded into the controller. Then, a high time response current control is applied into the grid inductor current, where a sinusoidal duty command $\left(D_{m c}\right)$ is used to generate the corresponding gate signals.

Figure 5 shows the principal control of the power decoupling. The relationship among the grid power $p_{g}$, battery power $p_{b a t}$, and capacitor power $p_{c b}$ is defined in Equation (2), where $p_{a v g}$ is the average power and $\mu_{0}$ is the grid phase angle. When subjected to the frequency of the grid power, the battery current contains twice the grid frequency.

$$
p_{g}=p_{b a t}-p_{c b} ; p_{c b}=p_{a v g} \cos \left(2 \omega_{0} t\right)
$$

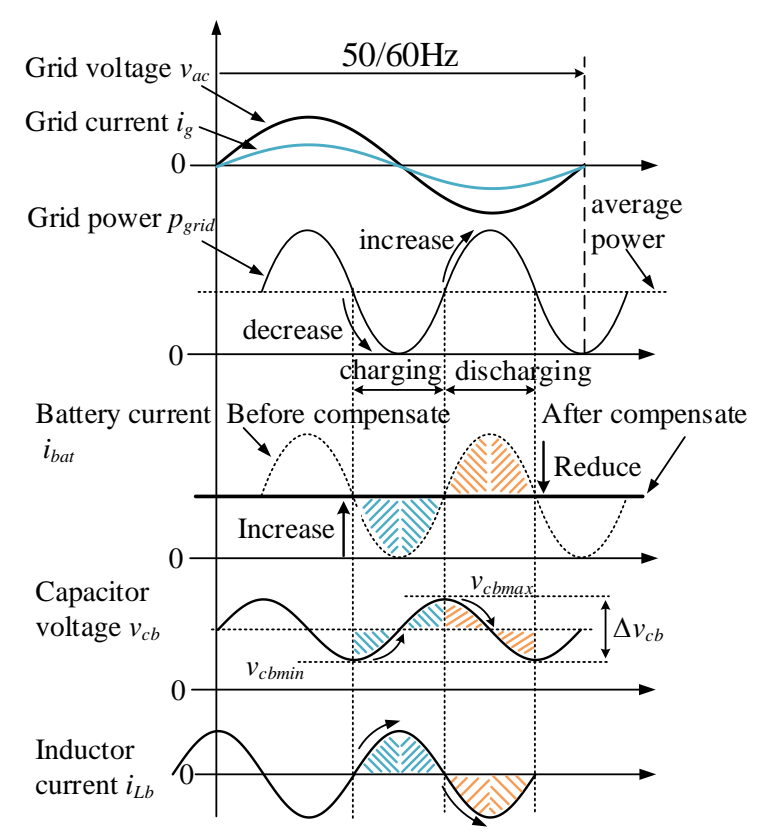

Figure 5. Principle control of power decoupling, charging and discharging states in the capacitor are used to compensate the single-phase current that occurs in the battery current.

In the power decoupling, the capacitor power is divided into a charging and discharging state. When the grid power is lower than the average power, this period is known as a charging state. During the charging state, the battery power is loaded into the capacitor by controlling the center-tapped inductor current. Then, the capacitor voltage difference $\Delta v_{c b}$ increases from $v_{c b \min }$ to $v_{c b \max }$ during this period.

When the grid power is higher than the average power, this period is known as a discharging state. During the discharging state, the previously charged power in the capacitor is discharged by the center-tapped inductor current. Then, the capacitor voltage difference $\Delta v_{c b}$ decreases from $v_{c b \max }$ to $v_{c b \min }$ during this period. Since no power delivery is needed from the battery, the battery current remains at its average value. By repeating these two cycles according to the grid phase angle, the capacitor voltage difference is controlled to compensate the single-phase current in the battery. 


\subsection{Switching Behaviors in FBI}

The switching behavior and current relationships in FBI are described. Figure 6 shows the relationships between the two current components (DC and AC) in the FBI. The DC current component occurs when the DC/DC conversion is performed between the battery voltage and capacitor voltage. In this case, the FBI is equivalent to a buck converter with a 180 degree phase shift. Two DC currents, $i_{L b 1}$ and $i_{L b 2}$, are manipulated with the duty to control the center-tap connected inductor current and capacitor voltage, which can be defined in Equations (3) and (4).

$$
\begin{aligned}
& v_{c b}=D_{f b i} \times v_{b a t} ; \\
& i_{L b}=i_{L b 1}+i_{L b 2} ;
\end{aligned}
$$

where $v_{c b}$ is the capacitor voltage, $v_{b a t}$ is the battery voltage, $D$ is the duty of FBI, and $i_{L b}$ is the inductor current.

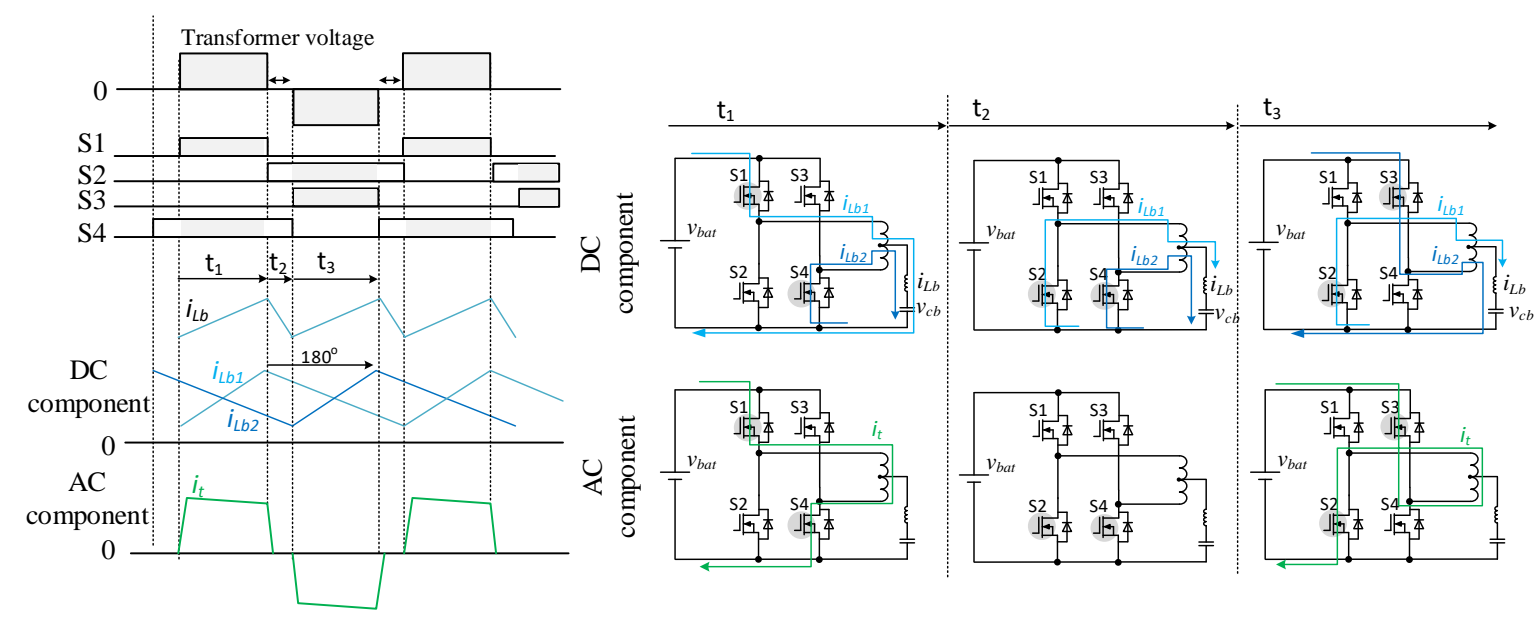

Figure 6. Relationship between the two current components in FBI.

On the other hand, the AC current component occurs when the battery power delivers the grid via the transformer, which is the transformer current. The AC current component is controlled with corresponding to the modulation of $\mathrm{MC}$, which is equivalent to the grid inductor current. Therefore, the relationship between the transformer current and grid inductor current can be expressed as Equation (5).

$$
i_{t p} \times N=i_{t s}=i_{g l}
$$

where $i_{t p}$ is the primary side current (FBI), $i_{t s}$ is the secondary side current (MC), $N$ is the transformer ratio, and $i_{g l}$ is the grid inductor current.

According to the state of the capacitor (charging or discharging) and the amplitude of the battery current, the total of four switching behaviors can be summarized as shown in Figure 7. The zero-voltage periods of FBI (S1S3 or S2S4 are turned on) are utilized to discharge and charge the inductor current.

During the discharging state, the battery current needs to be reduced and therefore the charged energy in the capacitor $C_{b}$ discharges to the battery side. When S2S4 are turned on, the current circulates via S2 and S4 to keep the charged energy. When S1S3 are turned on, the charged energy in the inductor is released to the battery via S1 and S3. The current cancellation between the battery current and inductor current reduces the high peak of the battery current.

During the charging state, the battery current needs to be increased and therefore the low peak of the battery current charges into the capacitor $C_{b}$. Here, when S1S3 are turned on, the battery current flows via S1 and S3 to charge inductor $L b$. Then, when S2S4 are turned on, the charged energy in the inductor circulates via switching devices. 


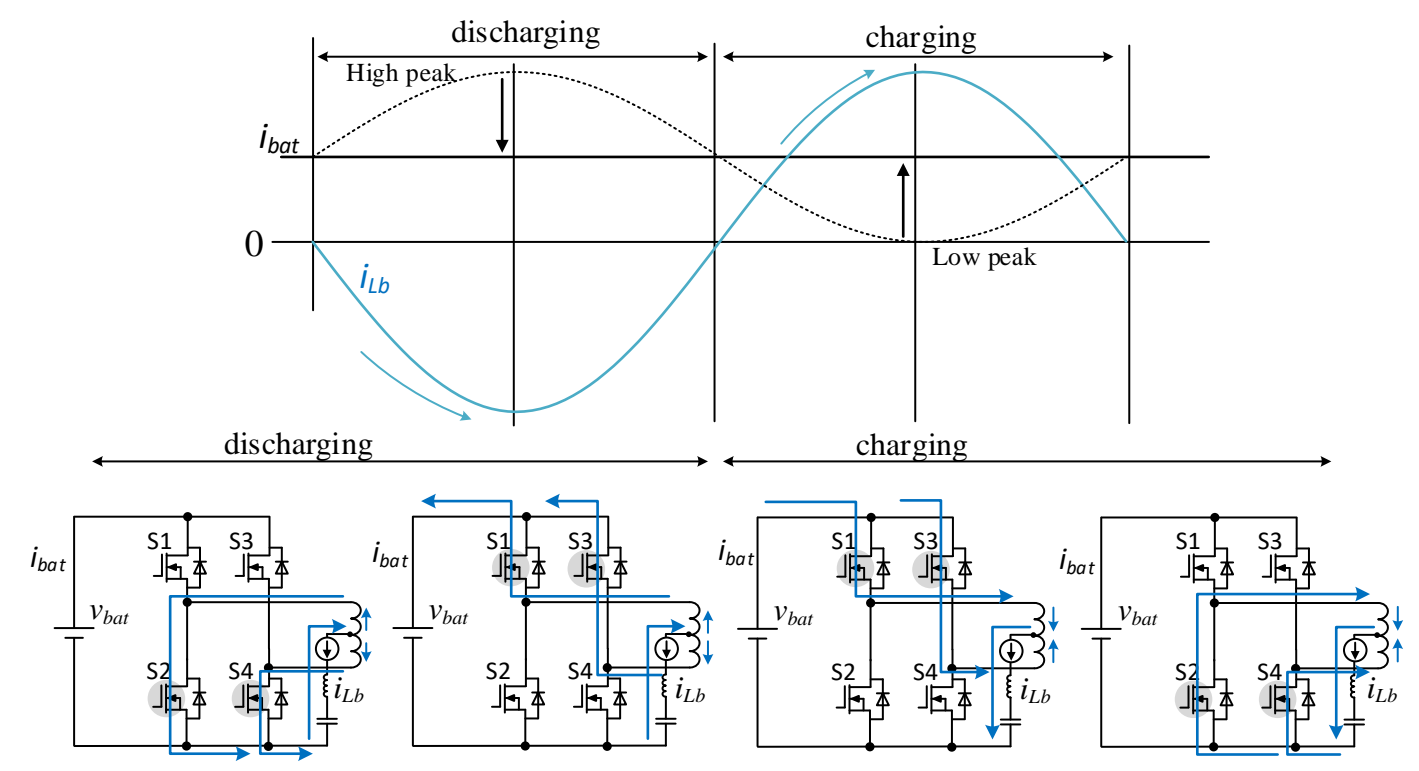

Figure 7. Switching behavior of full-bridge inverter (FBI) according to the state of capacitor and amplitude of the battery current.

\subsection{Modulation in MC}

In MC, a low frequency voltage pulse width is formed to control the grid inductor by accumulating from the high frequency transformer voltage $v_{t s}$. The high frequency transformer is controlled by FBI which is magnetized from the battery voltage. As shown in Figure 8, the switching sequence is divided into positive and negative voltage periods according to the polarity of the grid voltage. Then, each of these voltage periods is implemented with zero-vector periods in order to discharge the grid inductor current. As a result, the method of modulation is used to control the length of these voltage periods in order to control the $50 \mathrm{~Hz}$ grid inductor current sinusoidal.

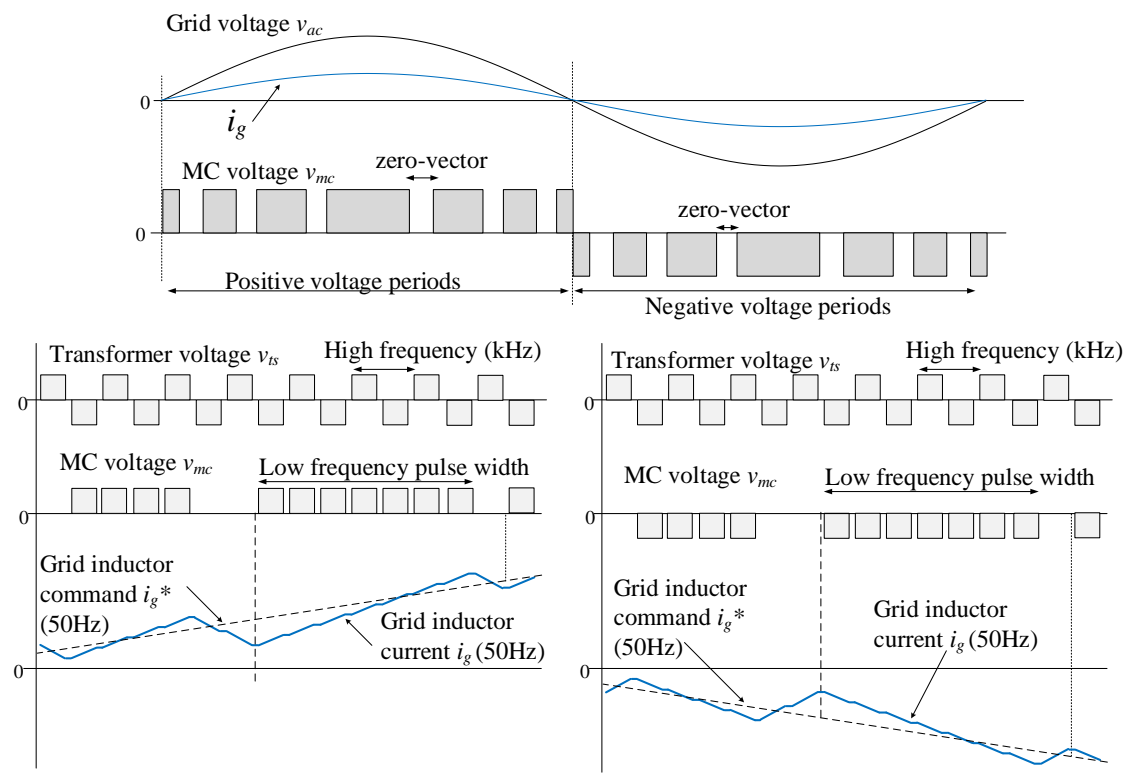

Figure 8. Modulation in matrix converter (MC), zero-vector periods are implemented in both positive and negative voltage periods. 
Figure 9a shows the switching behavior in MC, which can differ to normal switching states and zero-vector periods. When the gate signals S5S8 are turned on, the grid inductor is induced by the positive transformer voltage to charge the grid inductor. Otherwise, when the gate signals S6S7 are turned on, the grid inductor is then induced by the negative transformer voltage. On the other hand, when the gate signals S5S7 (or S6S8) are turned on, known as the zero-vector periods, a circulating loop is created inside the switching devices to allow the grid inductor current to circulate and discharge the energy in the grid inductor.

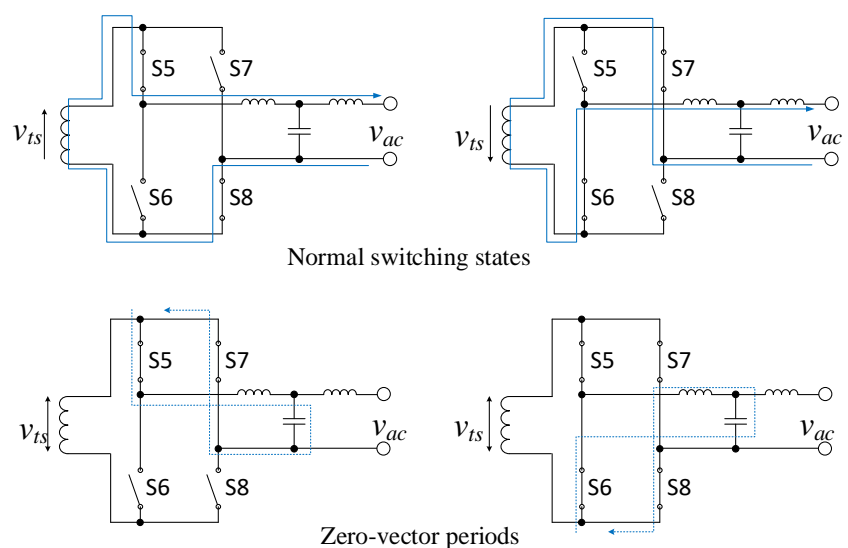

(a)

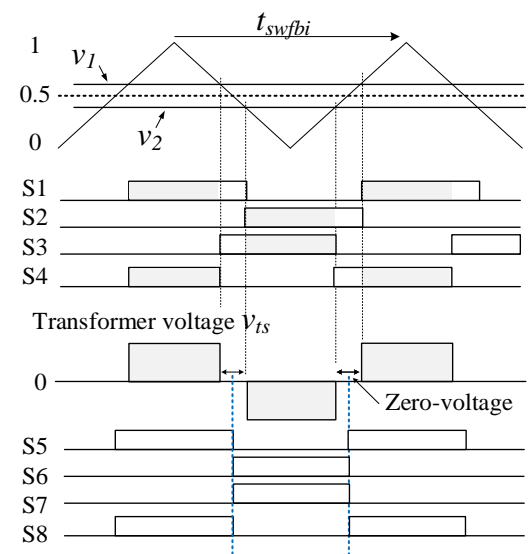

(b)

Figure 9. Switching behaviors in matrix converter (MC). (a) Normal switching states and zero-vector periods. (b) Zero-voltage switching (ZVS) relationship between full-bridge inverter (FBI) and matrix converter (MC).

Furthermore, Figure 9b illustrates the zero-voltage switching (ZVS) relationships between FBI and $\mathrm{MC}$. Since the transformer voltage is magnetized from the battery voltage, a three-level high frequency transformer voltage can be produced. That is, when gate signals S1 S3 or S2 S4 in FBI are turned on, no voltage-product occurrs in the MC. These zero-voltage periods are utilized in the switching intervals of MC to reduce the switching loss. During the gate-off transition, the drain-source voltage of switching devices drops to zero before the gate signal is turned off. Then, during the gate-on transition, the gate signal is turned on before the voltage is applied to the switching devices. Therefore, both of the transitions can achieve ZVS.

However, the leakage inductance of the transformer needs to be taken into consideration during the switching intervals. The energy in the leakage inductance needs to be discharged while the transformer current changes the direction. Here, the approach is to use the grid inductor current to cancel out with the leakage inductance current during the switching intervals. Figure 10 explains and illustrates the phenomenon, where the positive transformer voltage is changed to the negative transformer voltage while the grid side produces a positive voltage.

As shown in Figure 10, the transformer voltage becomes zero before the switching intervals start. Then, following that the $\mathrm{S} 6 \mathrm{AB}$ and $\mathrm{S} 7 \mathrm{AB}$ are turned on in the next switching interval. During this state, the leakage inductance current is used to discharge the capacitance S5A and also charge the capacitance S6B. At the same time, the grid inductor current is flowing via S6AB in a reverse direction, as a result the leakage inductance current and grid inductor current cancel out each other. The same phenomenon applies to $\mathrm{S} 7 \mathrm{AB}$ and $\mathrm{S} 8 \mathrm{AB}$, capacitance $\mathrm{S} 7 \mathrm{~B}$ is charged and capacitance $\mathrm{S} 8 \mathrm{~A}$ is discharged by the leakage inductance current. Then, the grid inductor current is flowing via S7BA in an opposite direction to achieve the current canceling.

As a result, forming an accurate voltage period, achieving ZVS, and current cancelling at the same time is important in the method of modulation. 


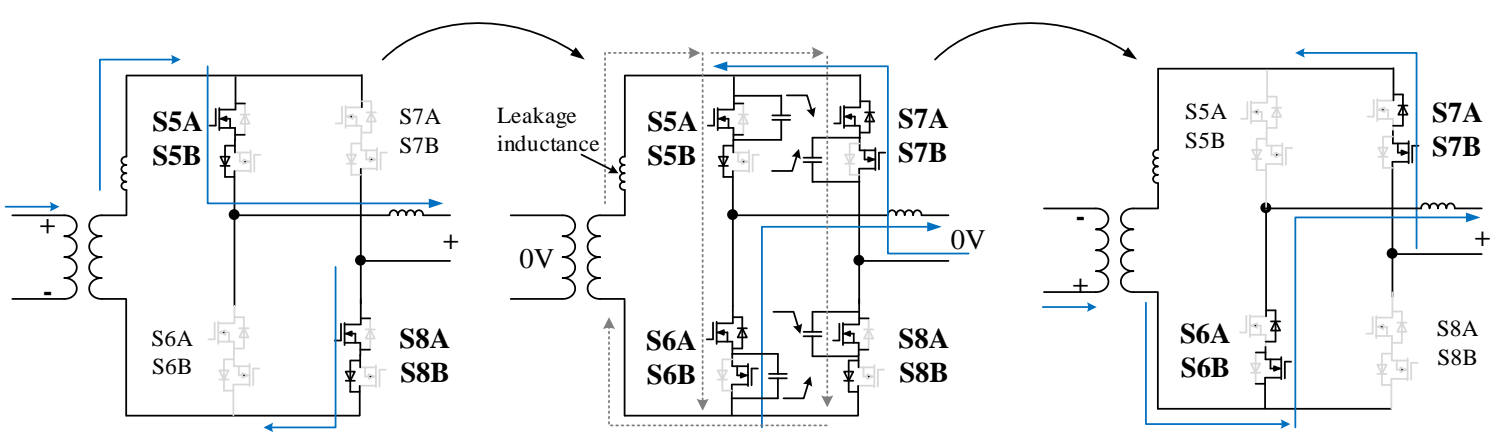

Figure 10. Current cancelling in matrix converter (MC) to discharge the leakage inductance current during switching intervals.

\section{Methods of Modulation}

\subsection{Carrier Comparison with D-FF (D-FlipFlop)}

The first method is to use a D-flipflop (D-FF) function, the control block diagram is shown in Figure 11. A carrier comparison with $D_{m c}$ is used to generate two sets of switching signals SPQ and SNQ. When SPQ and SNQ are both turned on zero-vector periods are formed. These two switching signals are inputted to a D-FF, where the D-FF is synchronized with the CLK, and a XNOR logic is applied to produce gate signals for S5-S8. The CLK is used to synchronize the switching intervals of MC with the zero-voltage periods of FBI in order to achieve ZVS.

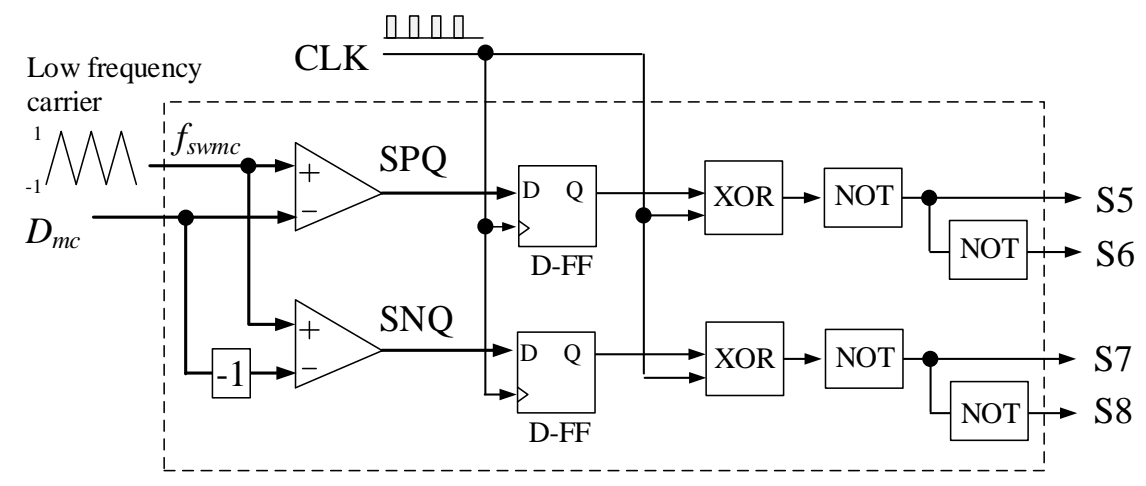

Figure 11. Carrier comparison with the D-flip flop block diagram.

However, D-FF creates a voltage error due to the occurrence of improper time length. Figure 12 shows the relationships among switching signals SPQ SNQ, gate signals S5-S8, and voltage pulse width. First, SPQ and SNQ form the required voltage pulse width accordingly based on the carrier comparison. After the SPQ and SNQ are aligned with D-FF, the voltage pulse width applied to the grid inductor either becomes longer or shorter than the original voltage pulse width. These improper pulse widths create voltage errors and the average grid inductor current is misadjusted. As a result the grid current fluctuates irregularly.

\subsection{Delta-Sigma Conversion with Pulse Density Modulation (PDM)}

In order to eliminate the voltage error, a delta-sigma conversion which is based on pulse density was discussed. Figure 12 shows the control block diagram and Figure 13 shows the relationship between duty $D_{m c}$ and quantization error $Q_{r}$. The carrier comparison is not applied because the integral changes corresponding to the quantization error. One cycle of the quantization level is equivalent to one cycle of the CLK. The $Q_{r}$ is obtained based on the differential value between the $D_{m c}$ and $D_{m c}$. Note that the amplitude of $D_{m c}$ does not change according to the grid current command $\left(i_{g}{ }^{*}\right)$ but the 
level of quantization error changes depending on the pulse density. As shown in Figure 14, the original middle point is $D_{m c}=0.5$. Then, the level of $Q_{r}$ changes depending on the pulse density that is used to form the grid current command, which is $Q_{r}>D_{m c}$ or $Q_{r}<D_{m c}$. The comparison between the $D_{m c}$ and $Q_{r}$ produces the corresponding voltage signals $\mathrm{Sa}$ and $\mathrm{Sb}$ in order to produce the desired voltage pulse width. EXOR logic is applied to $\mathrm{Sa}$ and $\mathrm{Sb}$ to synchronize with CLK in order to produce gate signals.

That is, when $i_{g}$ needs to increase, a longer voltage pulse width is required and therefore $Q_{r}$ gets higher than $D_{m c}$. On the other hand, when $i_{g}$ needs to decrease, a shorter voltage pulse is required and $Q_{r}$ gets lower than $D_{m c}$.

These phenomenon are illustrated in Figure 15, where (a) $Q_{r}<0.5$ and (b) $Q_{r}>0.5$. In Figure 15a, in order to decrease the grid current, most of the $Q_{r}$ periods are lower than $D_{m c}$, then Sa produces a short voltage signal only when $Q_{r}$ is higher than $D_{m c}$. On the other hand, in Figure $15 \mathrm{~b}$, in order to increase the grid current, a longer voltage pulse is required. Notice that the level of $Q_{r}$ increases, and most of the $Q_{r}$ periods are higher than $D_{m c}$ to produce the desired voltage pulse width. As a result, the grid current can be controlled sinusoidal without the voltage error, and ZVS can be achieved by synchronizing to CLK.

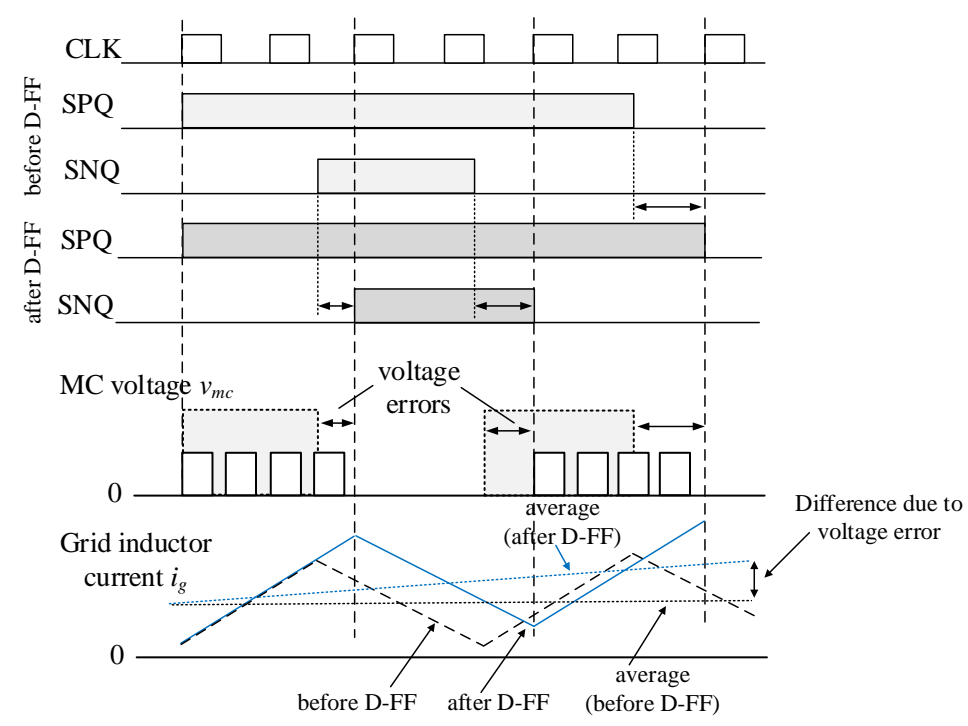

Figure 12. Relationship among CLK, SPQ, SNQ, MC voltage, and the grid inductor current are shown to demonstrate the voltage error in D-flip flop.

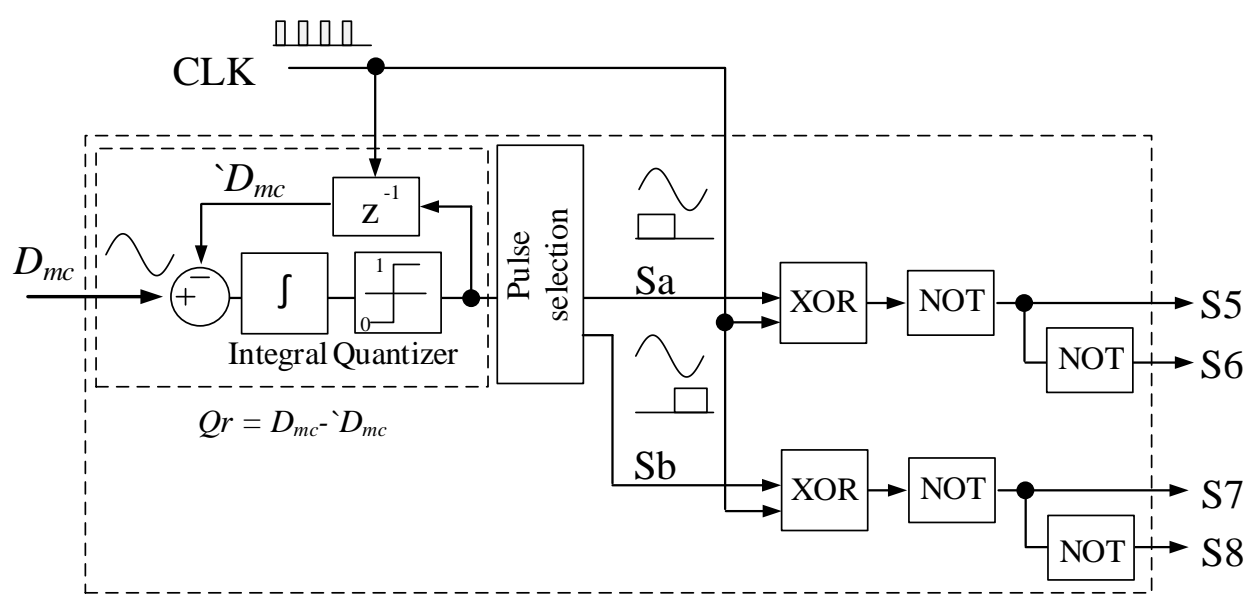

Figure 13. Delta-sigma conversion block diagram. 


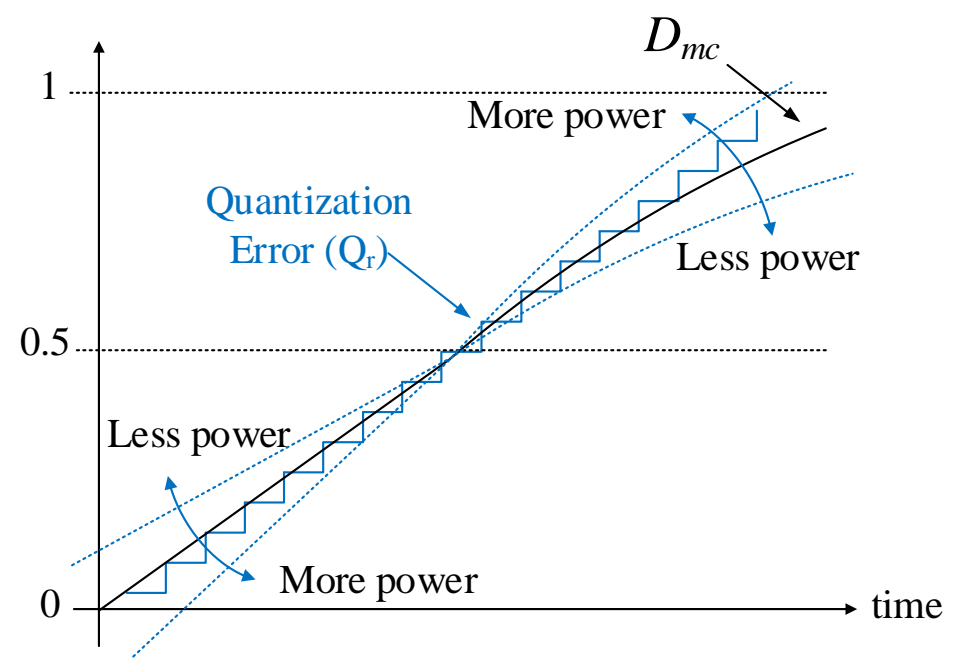

Figure 14. Principle control of delta-sigma, where quantization error changes according to the power level in order to obtain the desired pulse width $\left(Q_{r}>D_{m c}\right.$ or $\left.Q_{r}<D_{m c}\right)$.

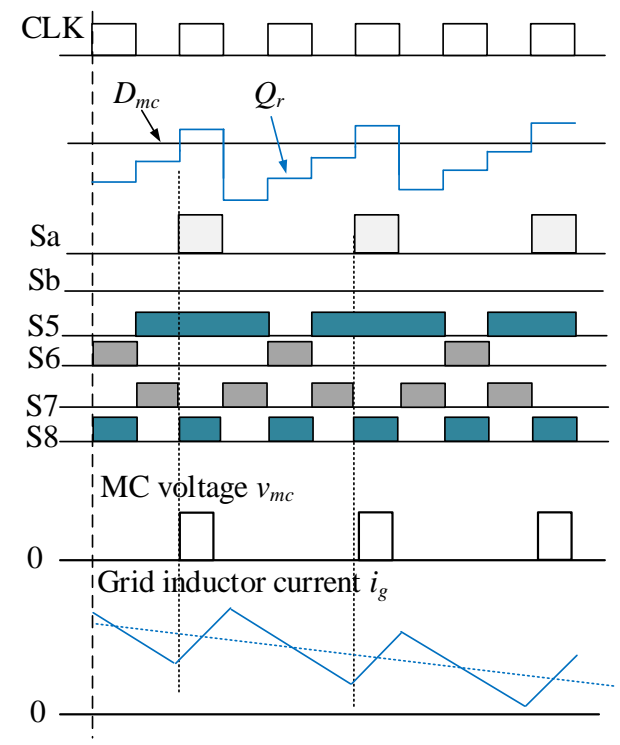

(a)

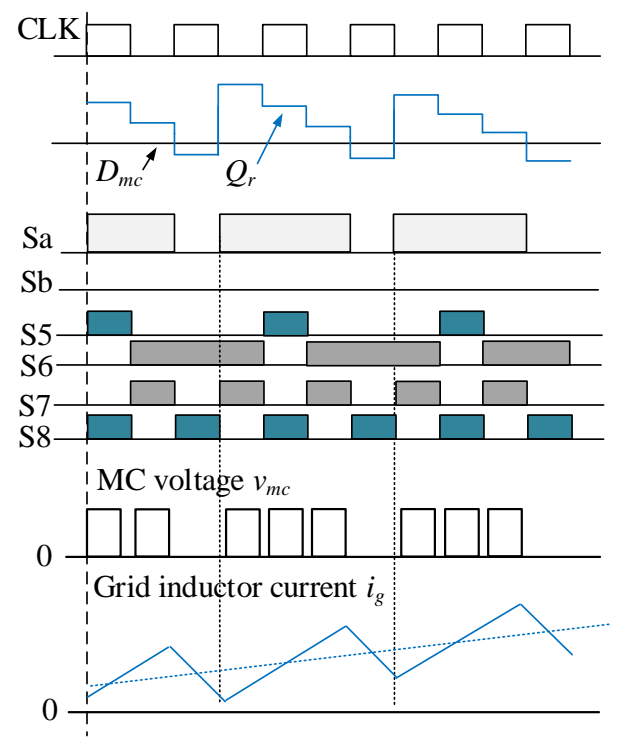

(b)

Figure 15. Relationship among CLK, $D_{m c}, Q_{r}$, MC voltage, and the grid inductor to demonstrate the control of delta-sigma. (a) $Q_{r}<0.5$. (b) $Q_{r}>0.5$.

However, without the carrier comparison the integral resets the value depending on the quantization level at a random frequency, as shown in Figure 16. As a result, the grid current ripple has an inconsistent frequency which causes a resonance problem during the low output power [18]. Furthermore, the resonance also occurs in the battery current due to the AC/AC direct conversion. Note that this resonance cannot be compensated in the single-phase power decoupling, therefore one approach is to decrease the cut-off frequency of the LCL; however, the size of LCL needs to increase as a drawback.

\subsection{Carrier Comparison with Zero-Vector Commutation}

The method of carrier comparison with zero-vector commutation is shown in Figure 17. This control is implemented with a constant frequency and a commutation to eliminate voltage error. A carrier comparison which is based on the pulse width modulation (PWM) is used and compared with $D_{m c}$ to generate a constant frequency voltage pulse width, similar to D-FF. Then, a zero-vector determination (FS-SYN) is used to distinguish between the normal switching states and zero-vector periods. During 
the normal switching states, the CLK synchronizes the switching timing so that each of the switching intervals of MC can achieve ZVS.

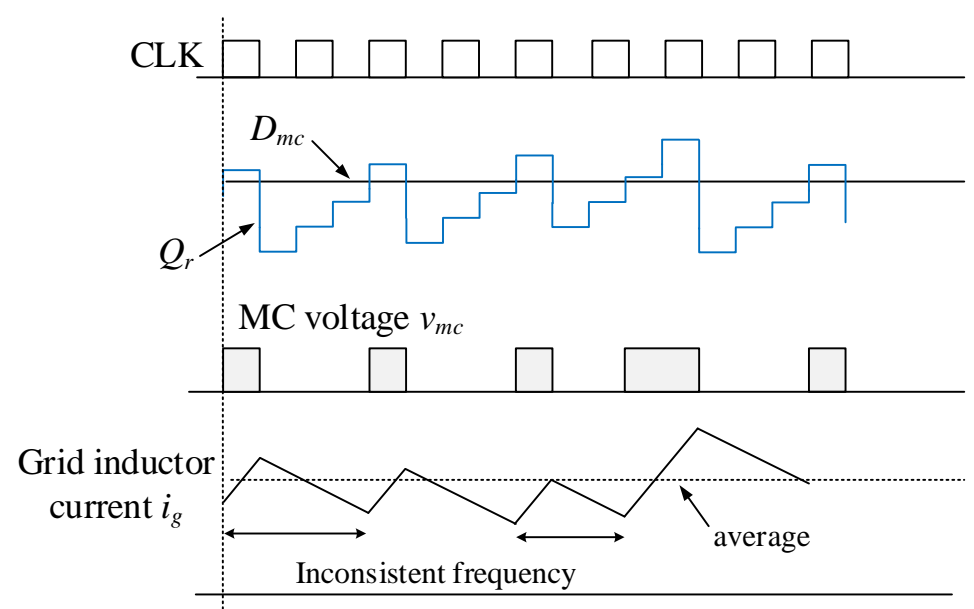

Figure 16. Inconsistent frequency in the grid inductor current due to the quantization error.

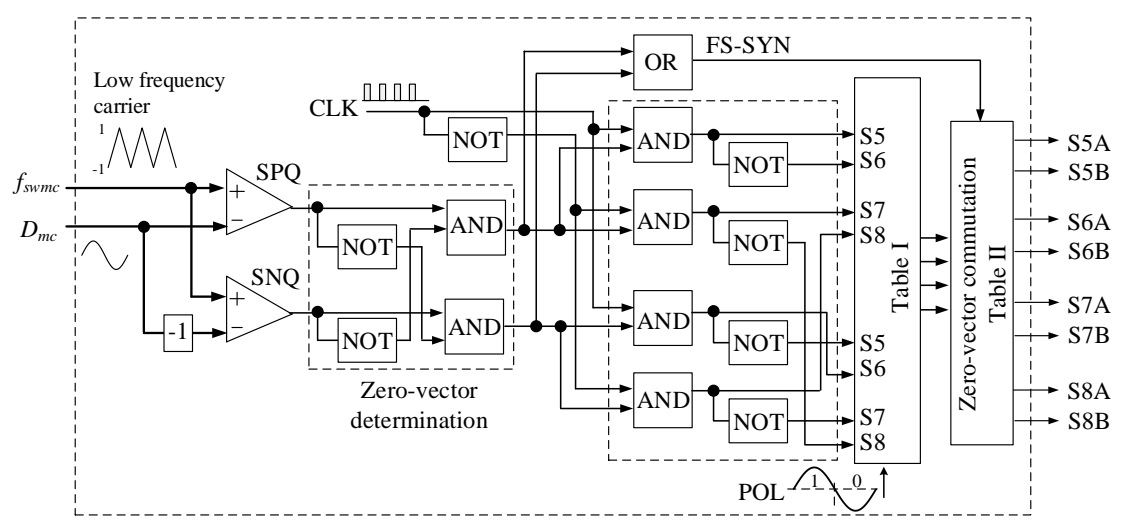

Figure 17. Carrier comparison with zero-vector commutation is introduced to overcome the voltage error and the inconsistent frequency problem.

During the zero-vector periods, since the transformer voltage is applied on the switching devices, hard-switching will cause the voltage at the switching device. In order to prevent the short-circuit state, the transformer current first needs to be blocked before switching. Furthermore, a current circulating path must first be created in order to achieve current cancelling.

The zero-vector commutation is applied only to the first and last switching intervals of the zero-vector periods. A total of six categories are divided in the zero-vector commutation which depends on the polarity of the transformer voltage, as shown in Figure 18. That is, if the zero-vector period occurs from a positive transformer voltage and ends on a positive voltage or ends on a negative voltage, it is known as PV-to-Z, PVZ-to-PV or PVZ-to-NV, respectively. On the other hand, if the zero-vector period occurs from a negative transformer voltage and ends on a positive voltage or ends on a negative voltage, it is known as NV-to-Z, NVZ-to-PV or NVZ-to-NV, respectively. Then, a two-step commutation is performed to circulate and cancel out the leakage inductance current. The switching algorithms of normal switching states are summarized in Table 1, and the switching algorithms of zero-vector commutation are summarized in Table 2. 

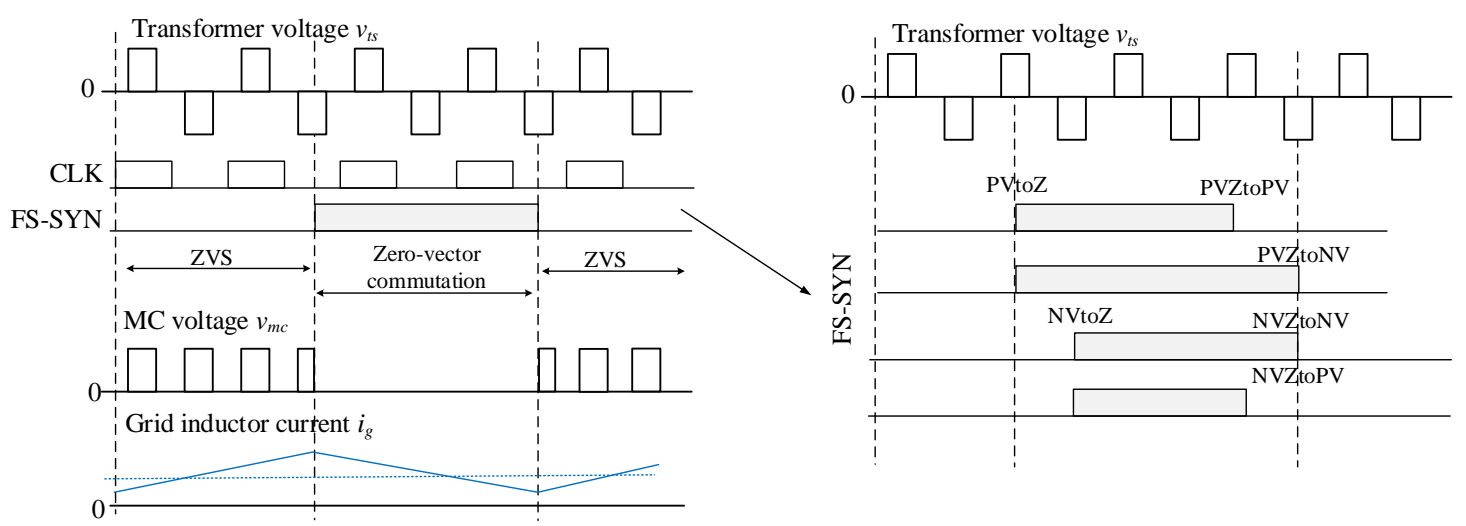

Figure 18. Categories of zero-vector commutation depending on the polarity of transformer voltage.

Table 1. Switching algorithms of normal switching states (ZVS).

\begin{tabular}{ccccccc}
\hline Symbols & \multicolumn{3}{c}{ Polarity $=\mathbf{1}$} & \multicolumn{3}{c}{ Polarity $=\mathbf{0}$} \\
\hline SPQ & 1 & 1 & 1 & 0 & 0 & 0 \\
SNQ & 0 & 0 & 1 & 1 & 1 & 1 \\
$V t s$ & + & - & $+/-$ & + & - & $+/-$ \\
S5 & 1 & 0 & 0 & 0 & 1 & 1 \\
S6 & 0 & 1 & 1 & 1 & 0 & 0 \\
S7 & 0 & 1 & 0 & 1 & 0 & 1 \\
S8 & 1 & 0 & 1 & 0 & 1 & 0 \\
$V m c$ & + & + & 0 & - & - & 0 \\
\hline
\end{tabular}

Table 2. Switching algorithms of zero-vector commutation.

\begin{tabular}{cccccccccccccc}
\hline Actions & \multicolumn{1}{c}{ PV-to-Z } & \multicolumn{1}{c}{ PVZ-to-PV } & \multicolumn{2}{c}{ PVZ-to-NV } & \multicolumn{2}{c}{ NV-to-Z } & \multicolumn{2}{c}{ NVZ-to-PV } & \multicolumn{2}{c}{ NVZ-to-NV } \\
\hline Sequence & 1st & 2nd & 1st & 2nd & 1st & 2nd & 1 st & 2nd & 1 st & 2nd & 1 st & 2nd \\
S5A & 1 & 1 & 1 & 1 & 1 & 0 & 0 & 0 & 1 & 1 & 0 & 0 \\
S5B & 1 & 1 & 1 & 1 & 0 & 0 & 0 & 0 & 0 & 1 & 0 & 0 \\
S6A & 0 & 0 & 0 & 0 & 1 & 1 & 1 & 1 & 0 & 0 & 1 & 1 \\
S6B & 0 & 0 & 0 & 0 & 0 & 1 & 1 & 1 & 1 & 0 & 1 & 1 \\
S7A & 0 & 1 & 0 & 0 & 1 & 1 & 0 & 0 & 0 & 0 & 1 & 1 \\
S7B & 1 & 1 & 1 & 0 & 1 & 1 & 1 & 0 & 0 & 0 & 0 & 1 \\
S8A & 1 & 0 & 0 & 1 & 0 & 0 & 1 & 1 & 1 & 1 & 1 & 0 \\
S8B & 0 & 0 & 1 & 1 & 0 & 0 & 0 & 1 & 1 & 1 & 0 & 0 \\
\hline
\end{tabular}

Figure 19 shows the switching sequence of the zero-vector commutation for the case PV-to-Z. First, S7B is turned on and S8B is turned off, the transformer current continues to flow in the same direction via the S8A and S8B diode. Then, as S8A is turned off, the capacitance in S8A is charged by the leakage inductance current in order to build up the blocking voltage. Thus, the capacitance in S7A is discharged to reduce the blocking voltage. At the same time, the grid inductor current flows in the opposite direction via $\mathrm{S} 7 \mathrm{AB}$ and therefore both currents are cancelled out with each other in $\mathrm{S} 7 \mathrm{AB}$. After $\mathrm{S} 8$ is completely turned off the grid inductor current starts circulating via $\mathrm{S} 5 \mathrm{AB}$ and $\mathrm{S} 7 \mathrm{AB}$, the zero-vector period is created in the grid side.

Figure 20 shows the switching sequence of the zero-vector commutation for the case PVZ-to-NV. First, S6A is turned on and S5B is turned off, the circulating current continues to flow in the same direction via $\mathrm{S} 5 \mathrm{AB}$ and $\mathrm{S} 7 \mathrm{AB}$. Then, as S6B is turned on, the capacitance in S5B is charged by the transformer current to build up the blocking voltage and capacitance in S6B is discharged. At the same time, the grid inductor current is cancelled out with the transformer current in S5AB. Since S5B is completely turned on, $\mathrm{S} 5 \mathrm{~A}$ is turned off at no loss and the transformer current starts to flow to the grid via $\mathrm{S} 6 \mathrm{AB}$ and $\mathrm{S} 7 \mathrm{AB}$. 


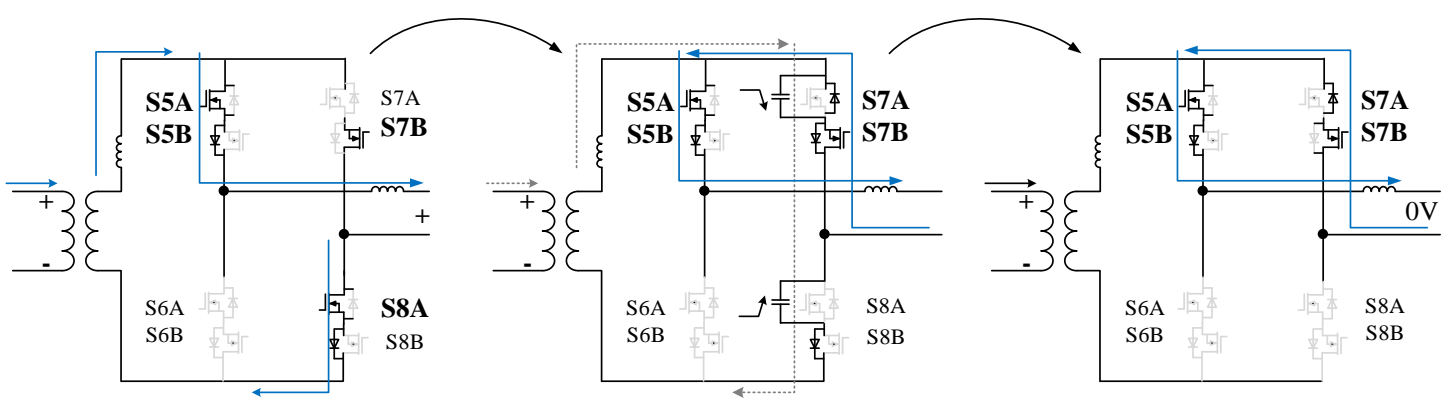

Figure 19. Switching sequence for PV-to-Z, current cancelling in S7AB.

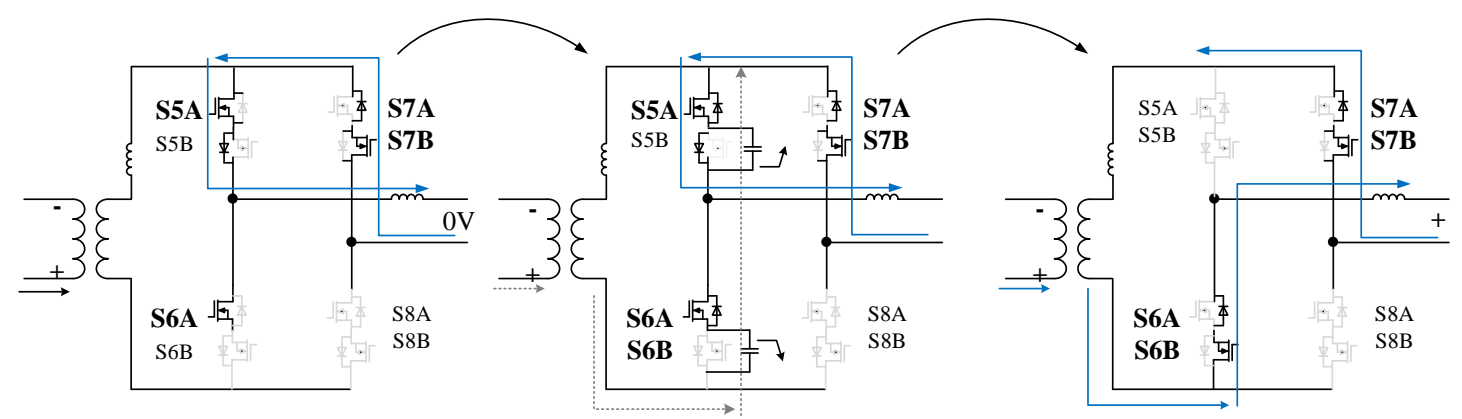

Figure 20. Switching sequence for PVZ-to-NZ, current cancelling in S5AB.

On one hand, for the case of PVZ-to-PV, current cancelling cannot be performed due to the polarity of transformer voltage. The differential current is creating a voltage surge but a short-circuit state is not created and therefore a breakdown of the device does not happen. Figure 21 explains the phenomenon of the switching sequence. First, S7A is turned off and S8B is turned on. Next, the capacitance in S8A needs to discharge in order to allow the current flows. Therefore, as S7B is turned off, the transformer current is charging the capacitance in S7A at the same time discharging the capacitance in S8A. Note that the only circulating path for the grid inductor current is via $\mathrm{S} 5 \mathrm{AB}$ and $\mathrm{S} 8 \mathrm{AB}$ and therefore the grid inductor current flows with the transformer current via $\mathrm{S} 8 \mathrm{AB}$ in the same direction. As a result, the voltage surge occurs while turning on S8AB.

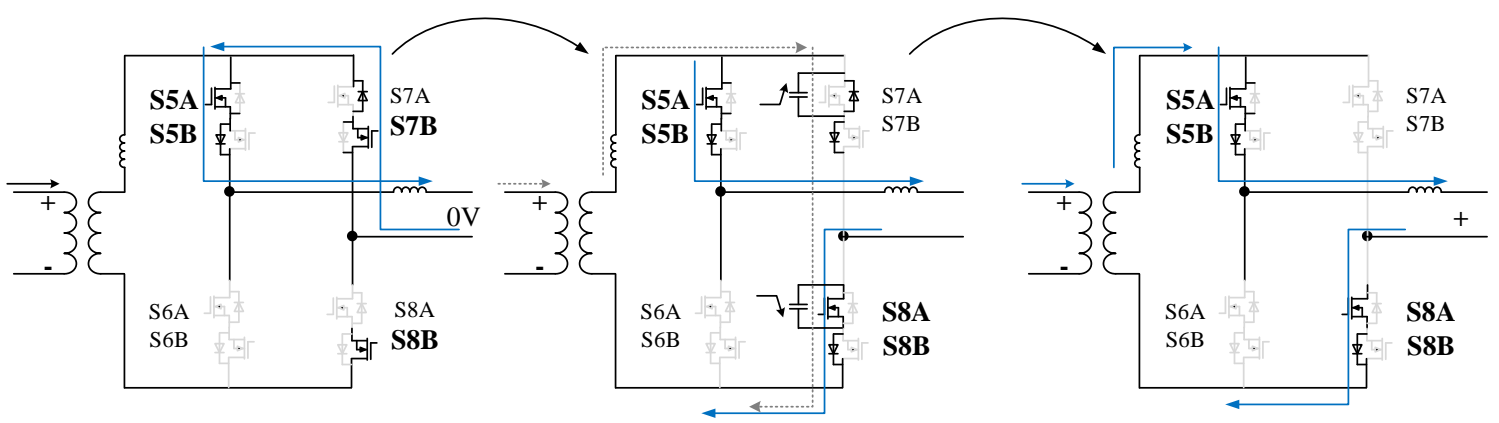

Figure 21. Switching sequence for PVZ-to-PV, current cancelling is not achieved.

Figures 22-24 illustrate the switching sequence for the case of negative transformer voltage. The principle control of current cancelling is similar, Figure 22 shows the switching sequence for NV-to-Z. While the transformer current is flowing via S6AB and S7AB, S8A is first turned on. Then, as S7B is turned off, the capacitance in S7B is charged and the capacitance S8B is discharged by the transformer current. At the same time, the grid inductor current flows via S8AB and current cancelling can be achieved in S8AB during this state. 


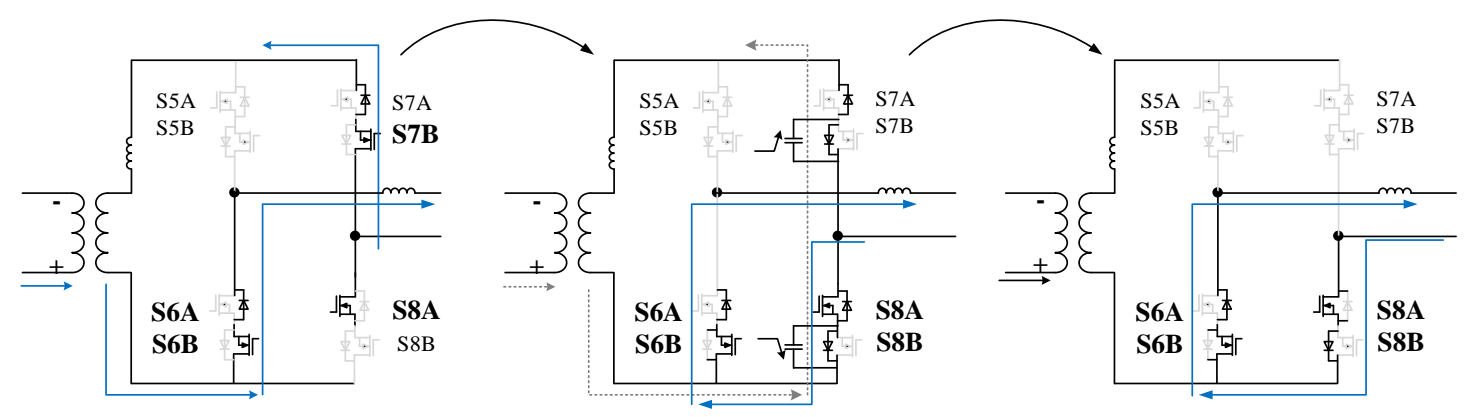

Figure 22. Switching sequence of NV-to-Z, current cancelling in S8AB.

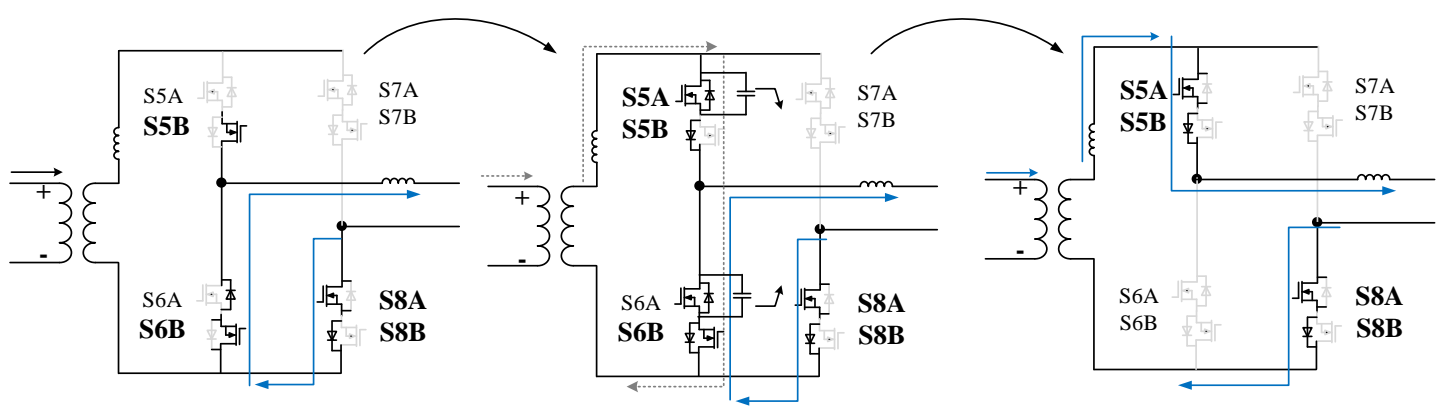

Figure 23. Switching sequence of NVZ-to-PV, current cancelling in S6AB.

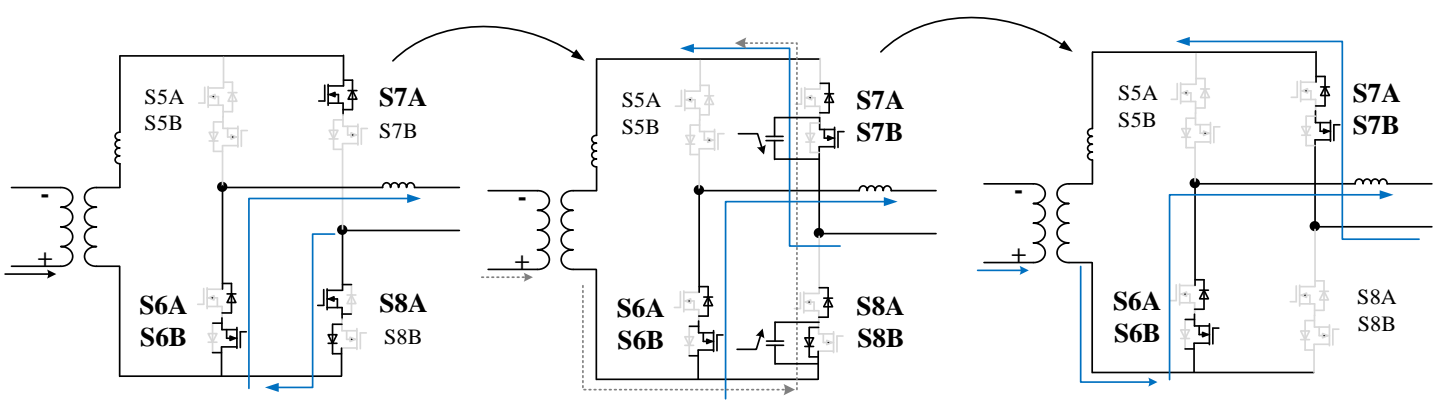

Figure 24. Switching sequence of NVZ-to-NZ, current cancelling is not achieved.

Figure 23 shows the switching sequence for NVZ-to-PV. While the grid inductor current is circulating via S6AB and S8AB, S5B is turned on and S6A is turned off. Then, as S5A is turned on, the capacitance in S5A is discharged and the capacitance in S6A is discharged by the transformer current. The grid inductor current flows in an opposite direction in $\mathrm{S} 6 \mathrm{AB}$ to achieve current cancelling. Since the S6A is completely turned on, the transformer current starts to flow via S5AB and S8AB. On the other hand, similar to PVZ-to-PV, current cancelling cannot be achieved in NVZ-to-NV. As shown in Figure 24, as S8B is turned on, the capacitance in S8B is charged and the capacitance in S7B is discharged by the transformer current. Due to this reason, the grid inductor current flows in the same direction with the transformer current in $\mathrm{S} 7 \mathrm{AB}$, and the voltage surge occurs during this interval.

Note that this zero-vector commutation differs from the traditional commutation in MC $[19,20]$. The traditional commutation is applied to form the voltage pulse width, however the zero-vector commutation is applied during the zero-vector periods only (no voltage-product). Therefore, the voltage error that occurred in the traditional commutation is not a concern. The purpose of the zero-vector commutation is to cancel the current while charging and discharging the capacitance in the switching devices, which is simpler than the traditional commutation. 


\section{Simulation Results}

The comparisons among the methods of modulation are demonstrated in the simulation results. The simulation parameters of each method are summarized in Table 3, which is similar to the experimental parameters. Moreover, the proportional-integral (PI) gain control for each method has been tuned to provide the best result. Figure 25 shows the relationships between transformer voltage, MC voltage, and grid inductor current based on the three modulations: (a) Carrier comparison with D-FF, (b) delta-sigma conversion with PDM, and (c) carrier comparison with zero-vector commutation, respectively.

Table 3. Simulation/experimental parameters.

\begin{tabular}{ccc}
\hline Names & Symbol & Value \\
\hline Battery voltage & $v_{b a t}$ & $100-200 \mathrm{~V}$ \\
Grid voltage & $v_{a c}$ & $100 \mathrm{~V} 50 \mathrm{~Hz}$ \\
Transformer voltage ratio & $N_{f b i}: N_{m c}$ & $1: 1.75$ \\
FBI switching frequency & $f_{s} w_{f} f b i$ & $100 \mathrm{kHz}$ \\
Capacitor & $C_{b}$ & $400 \mu \mathrm{F}$ \\
Inductor & $L_{b}$ & $10 \mu \mathrm{H}$ \\
MC switching frequency & $f_{s} w_{m} m c$ & $10 \mathrm{kHz}$ \\
Filter inductor & $L_{f}$ & $50 \mu \mathrm{H}$ \\
Filter capacitor & $C_{f}$ & $22 \mu \mathrm{F}$ \\
Grid inductor & $L_{g}$ & $425 \mu \mathrm{H}$ \\
\hline
\end{tabular}

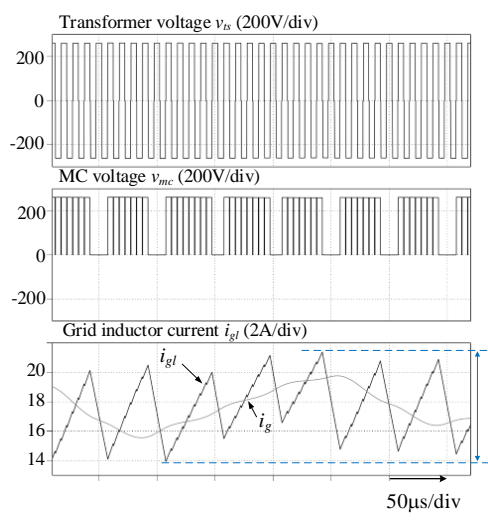

(a)

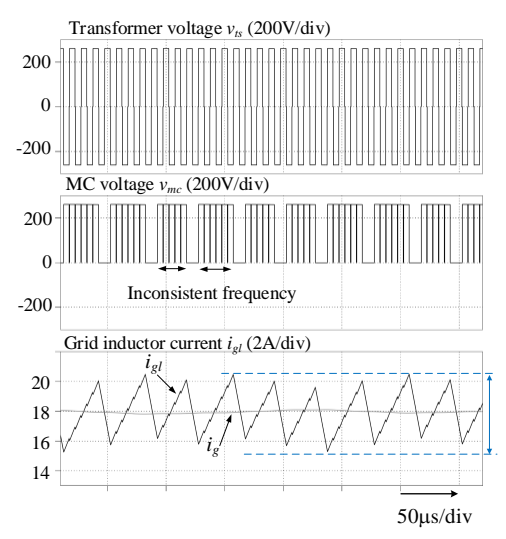

(b)

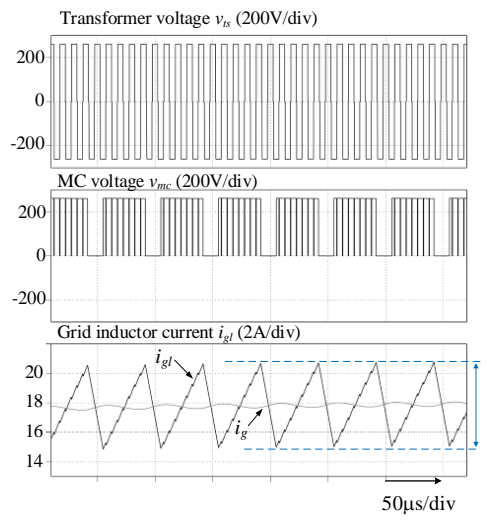

(c)

Figure 25. Simulation results that demonstrate the relationship between the matrix converter (MC) voltage pulse width and grid inductor current with different modulation methods. (a) D-flip flop, (b) delta-sigma conversion, (c) zero-vector commutation.

In the D-FF, it can be noticed that due to the misalignment of pulse width, the average of the grid current cannot be constantly controlled. As a result, the fluctuation of grid inductor current is the largest among the three methods. In the delta-sigma conversion, the voltage error can be resolved and therefore the fluctuation of grid inductor current is smaller than D-FF. However, it can be confirmed from the voltage pulse width that it has an inconsistent frequency due to the level of quantization error. With the zero-vector commutation, the voltage error can be eliminated and the fluctuation of grid inductor current is removed due to containing a consistent frequency in the current ripple. Therefore, the waveform quality can be improved as compared to the other two methods.

Figure 26 shows the simulation results at a low output power $(300 \mathrm{~W})$ that demonstrates the waveform of the battery current with all the three methods. Due to the direct AC/AC conversion, the distortion of grid current directly affects the waveform of the battery current. Notice that in Figure 26a, the battery current is heavily distorted in the D-FF because of the voltage error. In the case of delta-sigma conversion as shown in Figure 26b, the distortion in the battery current can be 
greatly reduced because the voltage error has resolved. However, a resonant frequency of the LCL filter occurrs at the battery current because of inconsistent frequency in the grid inductor current. As shown in Figure 26c, the zero-vector commutation can solve the two above problems. The distortion and resonance frequency in the battery current can both be removed due to a clean sinusoidal waveform that can be achieved in the grid inductor current.

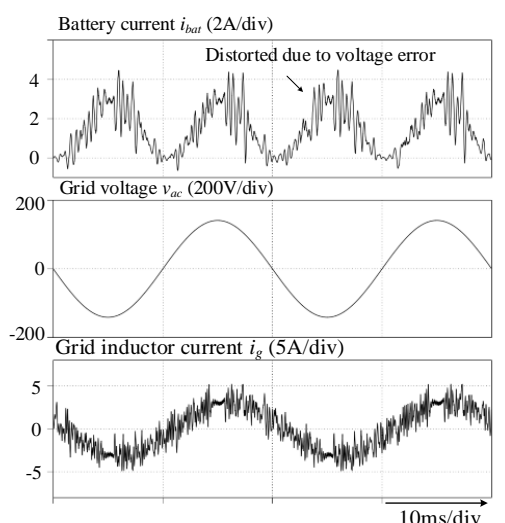

(a)

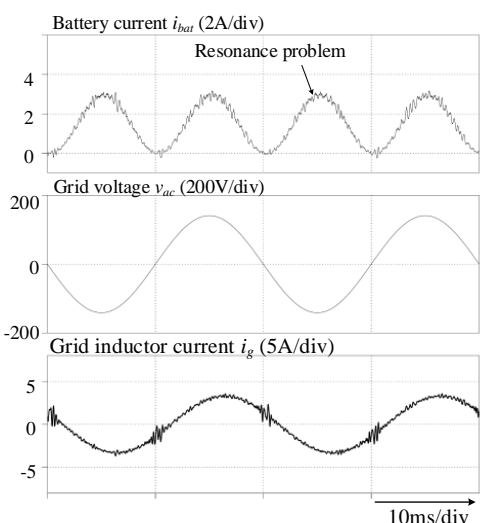

(b)

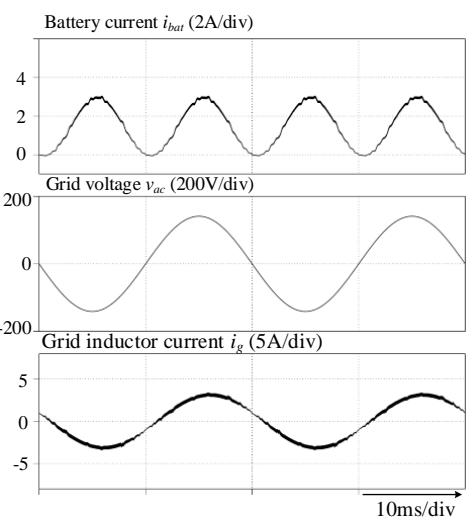

(c)

Figure 26. Low power $(300 \mathrm{~W})$ simulation result to demonstrate the differences of each method of modulation. (a) D-flip flop, (b) delta-sigma conversion, (c) zero-vector commutation.

Figure 27 shows another operating waveform at larger power $(3.3 \mathrm{~kW})$ to demonstrate the waveform of battery current with all the three modulation methods. D-FF is shown to have the worst distortion in battery current among the three methods. On the other hand, delta-sigma can achieve a clean sinusoidal waveform in the grid current nearly to the zero-vector commutation. This is because the peak-peak current is limited by the cut-off frequency of LCL filter, as the amplitude of the grid current becomes larger, the ripple current that is caused by the resonant frequency has lesser effect compared to the low power.

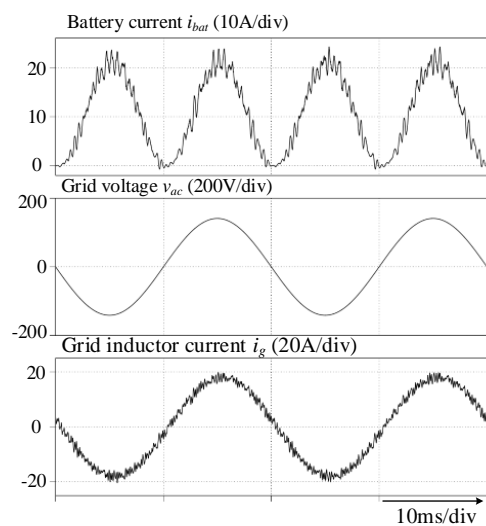

(a)

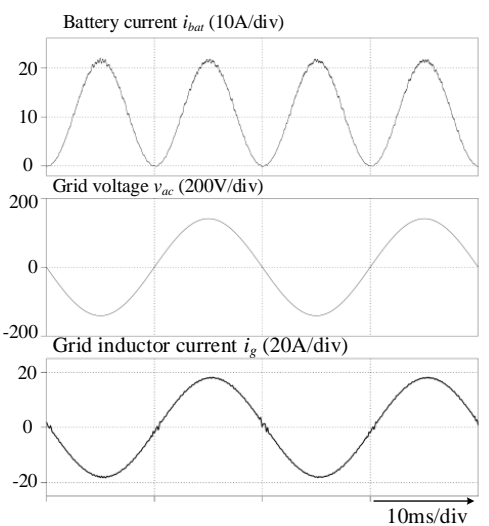

(b)

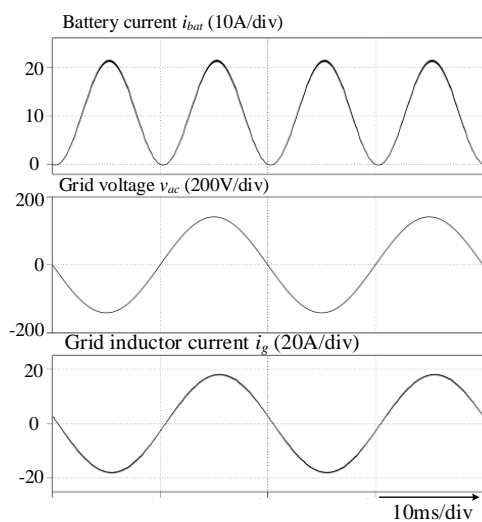

(c)

Figure 27. High power $(3.3 \mathrm{~kW})$ simulation result to demonstrate the difference of each method of modulation. (a) D-flip flop, (b) delta-sigma conversion, (c) zero-vector commutation.

Figure 28 shows the comparison of grid current THD among these modulations at low and high output power, respectively. The LCL cut-off frequency is regulated from 3 to $7.5 \mathrm{kHz}$ by adjusting inductor $L_{f}$ and the $C_{f}$ capacitor while keeping the same impedance percentage. The results in Figure 28a (low power) shows that D-FF has the highest THD, and only the zero-vector commutation can reach the THD below $5 \%$ at a cut-off frequency of $5 \mathrm{kHz}$. In Figure $28 \mathrm{~b}$ (high power), both the delta-sigma 
conversion and zero-vector commutation can reach the THD below $5 \%$ within the cut-off frequency from 3 to $7.5 \mathrm{kHz}$.

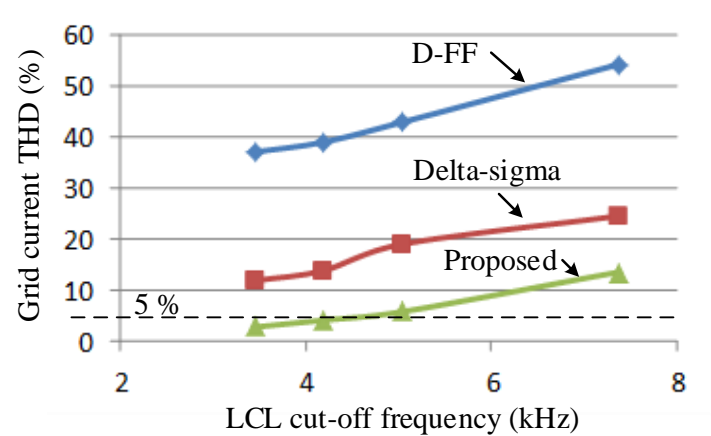

(a)

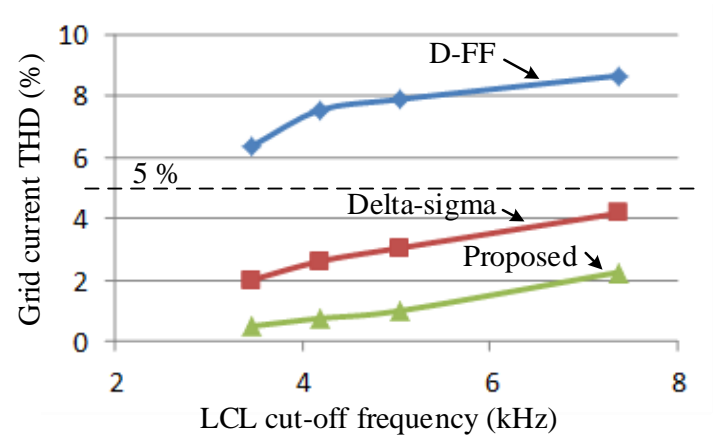

(b)

Figure 28. Comparison of grid current total harmonic distortion (THD) with the different inductivecapacitive-inductive (LCL) cut-off frequency between low power and high power. Zero-vector commutation achieves the lowest total harmonic distortion (THD) regardless of power level. (a) Low power (300 W).

(b) High power $(3 \mathrm{k} \mathrm{W})$.

As a result, in order for the delta-sigma control to achieve 5\% THD at low output power, the cut-off frequency needs to be reduced with the penalty of a larger size in the LCL filter. Therefore, the zero-vector commutation can achieve the smallest size in the LCL filter and also achieve THD below $5 \%$ for both low and high output power, among the three methods.

\section{Experimental Results}

Figure 29 shows the layout of the $1 \mathrm{~kW}$ prototype $(203 \times 113 \times 10 \mathrm{~mm})$. Switching devices are placed on both sides (left: MC; right: FBI), then a planer transformer is placed in the middle and the capacitor $C_{b}(400 \mu \mathrm{F})$ and an inductor $L_{b}(10 \mu \mathrm{H})$ that is connected to the center point of transformer is placed on the top side of the prototype.

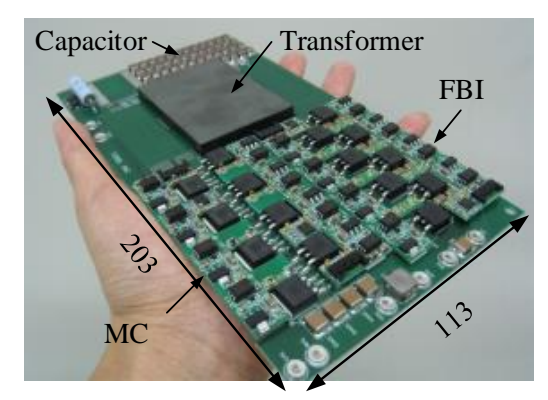

Figure 29. Layout of a $1 \mathrm{~kW}$ prototype.

Figure 30 shows the effectiveness of ZVS and zero-vector commutation. Figure 30a shows the result before applying zero-vector commutation. During the first (PV-to-Z) and last (PVZ-to-PV) switching intervals of zero-vector periods because hard-switching happens at a short-circuit state, therefore over-voltage occurrs at the transformer voltage. On the other hand, during the ZVS periods it can be confirmed that voltage spikes did not occur at the transformer voltage because switching devices are aligned to the zero-voltage of the transformer to achieve ZVS.

Figure 30b shows the result after applying the zero-vector commutation. As shown in the result, the voltage spike at the transformer voltage can be greatly reduced in PV-to-Z, comparing that to Figure 30a. The zero-vector commutation enables the switching state to go into the zero-vector periods to allow the current to circulate inside a loop and achieve current cancelling. As a result, the voltage 
spike of the switching device during the zero-vector periods can be resolved. On one hand, current cancelling cannot be achieved in PVZ-to-PV and therefore the voltage surge occurs on the transformer voltage. Since the short-circuit state can be prevented, the voltage surge is smaller than that compared to Figure 30a.

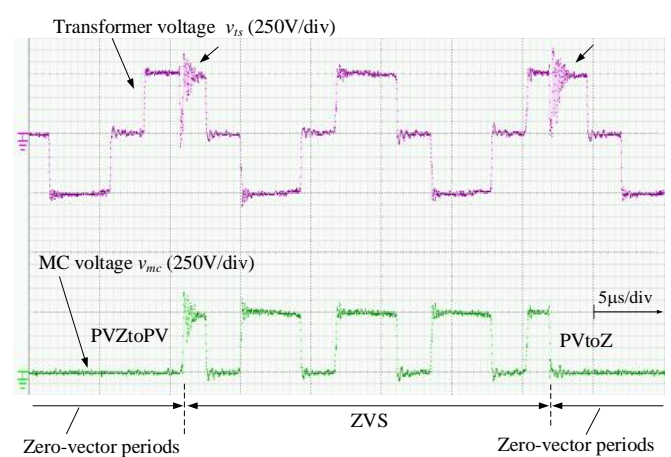

(a)

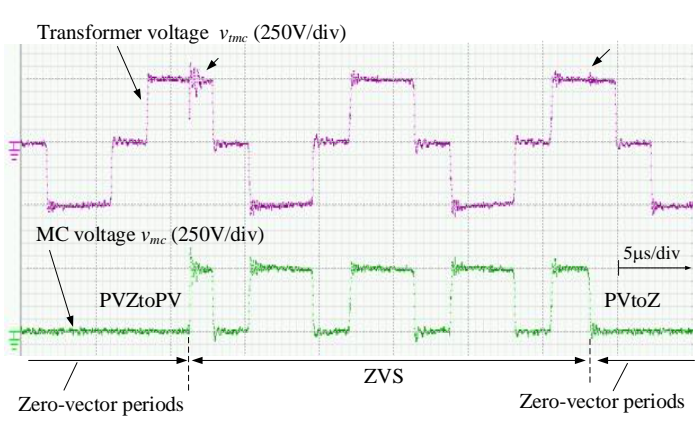

(b)

Figure 30. Experimental result to demonstrate the effectiveness of the zero-voltage switching (ZVS) and zero-commutation. (a) Without the zero-vector commutation. (b) With the zero-vector commutation.

The comparison of experimental results at low output power $(300 \mathrm{~W})$ between the delta-sigma and zero-commutation is shown in Figure 31a,b. In this result, the power decoupling was disabled in order to validate the effectiveness of the method of modulation. The capacitor voltage $v_{c b}$ is controlled at $90 \mathrm{~V}$ constantly with a battery voltage of $180 \mathrm{~V}$. In Figure 31a, we noticed that the grid inductor current $i_{g l}$ has a huge current ripple due to the inconsistent frequency. As a result, the battery current fluctuates at a resonance frequency of $1.25 \mathrm{kHz}$. Figure $30 \mathrm{~b}$ shows the results obtained by the zero-vector commutation, the distortion in the battery current can be nearly eliminated because a clean sinusoidal grid inductor current can be obtained.

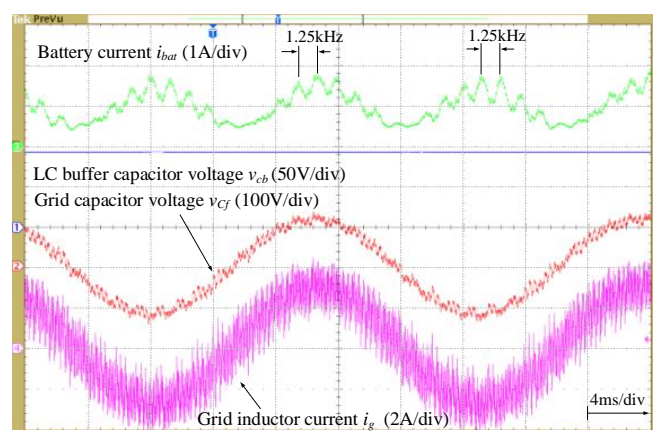

(a)

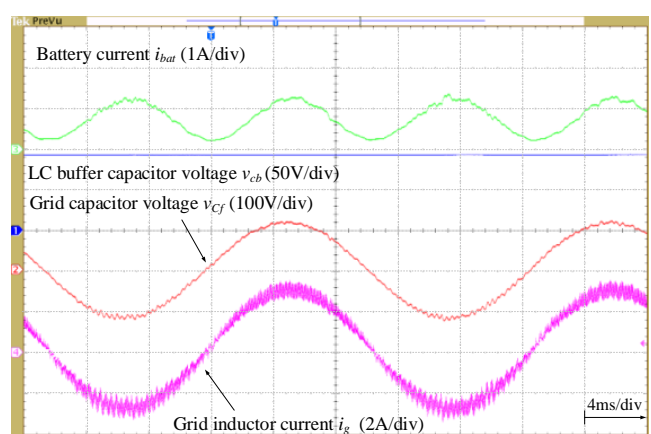

(b)

Figure 31. Comparison of experimental results between delta-sigma and zero-vector commutation. (a) Delta-sigma shows fluctuation in the battery current at $1.25 \mathrm{kHz}$. (b) Zero-vector commutation shows a clean sinusoidal waveform that can be obtained in the grid inductor current and battery current.

Figure 32a,b shows the fast Fourier transform (FFT) analysis of the grid current between the delta-sigma and the zero-vector commutation, respectively. Even the number of harmonic components contains the battery current. Then, it can be noticed that the 4th, 6th, and 8th harmonic components in the delta-sigma conversion is higher than that of the zero-vector commutation. The result can confirm that the zero-vector commutation could achieve better THD than the conventional ones.

Figure 33 shows the effectiveness of power decoupling with the zero-vector commutation. In Figure 33a, the power decoupling control was disabled and therefore the battery current contains a low frequency component. Then, after being applied to the power decoupling control as shown in 
Figure 33b, the single-phase power fluctuation occurs in the capacitor voltage. The average capacitor voltage is constantly kept at half of the battery voltage, then $\Delta v_{c b}$ of approximately $30 \mathrm{~V}$ is controlled at $100 \mathrm{~Hz}$ sinusoidal waveform to compensate the single-phase power fluctuation. This is also identical to the theoretical calculation which is explained in Figure 3, where a $400 \mu \mathrm{F}$ capacitor with $30 \mathrm{~V}$ voltage difference is designed for the power decoupling. As a result, the single-phase power fluctuation can be reduced in the battery current. Note that the low frequency fluctuation occurrs in the battery current because of the DC bias effect in the ceramic capacitor.

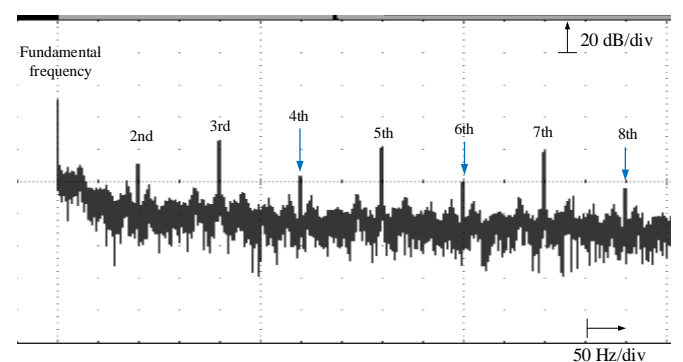

(a)

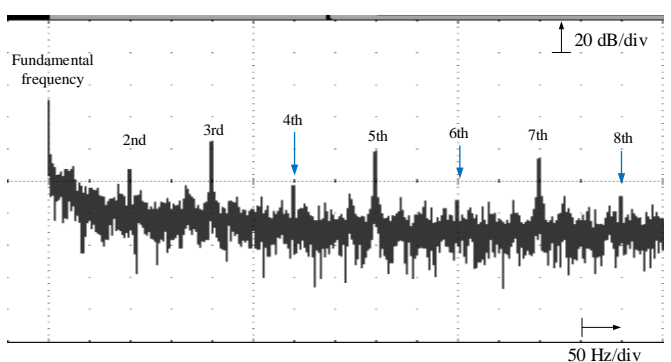

(b)

Figure 32. Comparison of the fast Fourier transform (FFT) analysis on grid current between delta-sigma and zero-vector commutation, the even harmonic component is lower in the zero-vector commutation. (a) Delta-sigma. (b) Zero-vector commutation.

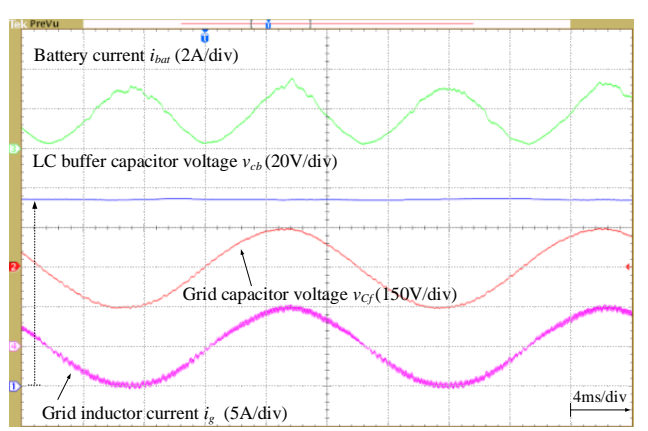

(a)

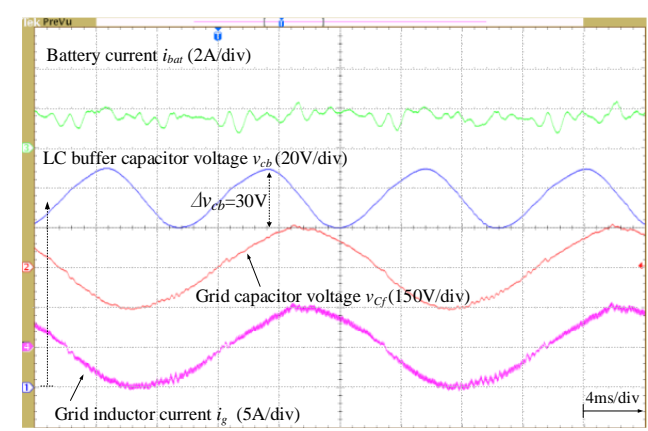

(b)

Figure 33. Experimental results to demonstrate the effectiveness of power decoupling control with the zero-vector commutation. (a) Without the decoupling control; capacitor voltage is constantly controlled at the average of battery voltage. (b) With the decoupling control; the capacitor voltage difference is $30 \mathrm{~V}$ with the decoupling control to compensate the single-phase power fluctuation.

Figure 34 shows the experimental measurement efficiency of the prototype. The prototype achieves the highest efficiency $91.5 \%$ at $1 \mathrm{~kW}$. Optimization of the losses will be considered in the future work to improve the efficiency.

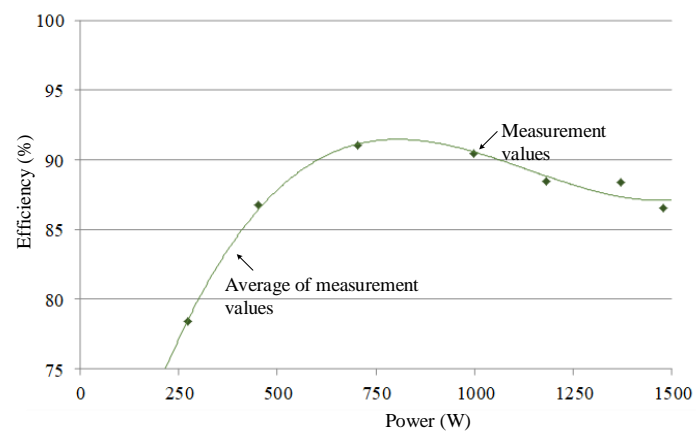

Figure 34. Measurement of efficiency, the prototype achieves the highest efficiency of $91.5 \%$. 


\section{Conclusions}

The comparisons among the three methods and along with other literature reviews are summarized in Table 4. Power decoupling is obviously not considered in the past studies due to the difference of circuit structure. The control also shows a difficult level due to complex commutation rules. This paper describes and compares three methods of modulation of $\mathrm{MC}$ for the power decoupling with the transformer integration. Zero-vector communication is introduced in this paper. The effectiveness of these modulations have been demonstrated in simulation and experimental.

Table 4. Comparison results among the three methods of modulation.

\begin{tabular}{|c|c|c|c|c|c|}
\hline \multirow[t]{2}{*}{ Modulation Methods } & \multirow{2}{*}{$\begin{array}{c}\text { Power } \\
\text { Decoupling }\end{array}$} & \multirow[t]{2}{*}{$\begin{array}{l}\text { Control } \\
\text { Complexity }\end{array}$} & \multicolumn{2}{|c|}{$\begin{array}{l}\text { Quality Waveform (Grid Current } \\
\text { THD, Battery Current Ripple) }\end{array}$} & \multirow[t]{2}{*}{ LCL Filter Sizing } \\
\hline & & & Low-Power & High-Power & \\
\hline SPWM synchronous rec. [12] & $\times$ & $\Delta$ & $\bigcirc$ & $\bigcirc$ & $\begin{array}{c}50 \mathrm{kHz} \\
L_{f}: 10 \mu \mathrm{H} \mathrm{C} C_{f: 1 \mu \mathrm{F}}\end{array}$ \\
\hline PWM four-step comm. [13] & $x$ & $x$ & $\bigcirc$ & $\bigcirc$ & $\begin{array}{c}5 \mathrm{kHz} \\
L_{f}: 300 \mu \mathrm{H} \mathrm{C} C_{f}: 4.7 \mu \mathrm{F}\end{array}$ \\
\hline PWM comm. [14] & $\times$ & $x$ & $\Delta$ & $\bigcirc$ & $\mathrm{N} / \mathrm{A}$ \\
\hline D-FF [15] & $\bigcirc$ & $\bigcirc$ & $x$ & $\Delta$ & $\begin{array}{c}\times \\
3 \mathrm{kHz} \\
L_{f}: 100 \mu \mathrm{H} \mathrm{C} C_{f}: 22 \mu \mathrm{F}\end{array}$ \\
\hline Delta-sigma [16] & $\bigcirc$ & $\Delta$ & $\Delta$ & $\bigcirc$ & $\begin{array}{c}\Delta \\
2 \mathrm{kHz} \\
L_{f}: 100 \mu \mathrm{H} \mathrm{C} C_{f}: 45 \mu \mathrm{F} \\
\bigcirc\end{array}$ \\
\hline Zero-vector commutation & $\bigcirc$ & $\Delta$ & $\bigcirc$ & $\bigcirc$ & $\begin{array}{c}5 \mathrm{kHz} \\
L_{f}: 50 \mu \mathrm{H} \mathrm{C} C_{f}: 22 \mu \mathrm{F}\end{array}$ \\
\hline
\end{tabular}

Modulations that consider the power decoupling are summarized as follows. The D-FF is simple in terms of control but the quality waveform is poor due to the voltage error. Delta-sigma achieves average among the three, in order to improve the THD during low-power, a bigger size of LCL filter is required. The zero-vector commutation can produce a better quality waveform but the control complexity requires a high-bandwidth controller. If the design level is only concerned for high-power, delta-sigma with a lower bandwidth controller is another option of choice.

Author Contributions: Conceptualization, G.T.C. and T.S.; methodology, G.T.C.; software, G.T.C.; validation, G.T.C. and T.S.; formal analysis, G.T.C.; investigation, G.T.C.; resources, G.T.C.; data curation, G.T.C.; writing-original draft preparation, G.T.C.; writing-review and editing, G.T.C. and T.S.; visualization, G.T.C.; supervision, T.S.; project administration, T.S.; funding acquisition, T.S. All authors have read and agreed to the published version of the manuscript.

Funding: This research received no external funding.

Conflicts of Interest: The authors declare no conflict of interest.

\section{References}

1. Raggl, K.; Nussbaumer, T.; Doerig, G.; Biela, J.; Kolar, J.W. Comprehensive design and optimization of a high-power density single-phase PFC. IEEE Trans. Ind. Electron. 2009, 56, 2574-2587. [CrossRef]

2. Choi, W.; Rho, K.-M.; Cho, B.-H. Fundamental duty modulation of dual-active bridge converter for wide-range operation. IEEE Trans. Power Electron. 2016, 31, 4048-4606. [CrossRef]

3. Jovanovic, M.M.; Jang, Y. State-of-the art, single-phase, active power factor correction techniques for high power applications. IEEE Trans. Ind. Electron. 2009, 56, 2574-2587. [CrossRef]

4. Musavi, F.; Eberle, W.; Dunford, W.G. A high-performance single-phase bridgeless interleaved PFC converter for plug-in hybrid electric vehicle battery chargers. IEEE Trans. Ind. Appl. 2011, 47, 1833-1843. [CrossRef] 
5. Xue, L.; Shen, Z.; Boroyevich, D.; Mattavelli, P. GaN-based high frequency totem-pole bridgeless PFC design with digital implementation. In Proceedings of the IEEE Applied Power Electronics Conference and Exposition (APEC), Charlotte, NC, USA, 15-19 March 2015; pp. 759-766.

6. Kolar, J.W.; Friedli, T.; Rodriguez, J.; Wheeler, P.W. Review of three-phase PWM AC-AC converter topologies. IEEE Trans. Ind. Electron. 2011, 58, 11. [CrossRef]

7. Empringham, L.; Kolar, J.W.; Rodrigues, J.; Wheeler, P.W.; Clare, J.C. Technological issues and industrial application of matrix converters: A review. IEEE Trans. Ind. Electron. 2013, 60, 10. [CrossRef]

8. Sun, Y.; Liu, Y.; Su, M.; Xiong, W.; Yang, J. Review of active power decoupling topologies in single-phase systems. IEEE Trans. Power Electron. 2016, 31, 4778-4794. [CrossRef]

9. Komeda, S.; Fujita, H. A power decoupling control method for an isolated sing-phase AC-to-DC converter based on direct AC-to-AC converter topology. IEEE Trans. Power Electron. 2018, 33, 9691-9698. [CrossRef]

10. Itoh, J.-I.; Hayashi, F. ripple current reduction of a fuel cell for a single-phase isolated converter using a DC active filter with a center tap. IEEE Trans. Power Electron. 2009, 25, 550-556. [CrossRef]

11. Takaoka, N.; Takahashi, H.; Itoh, J.-I. Isolated single-phase matrix converter using center-tapped transformer for power decoupling capability. IEEE Trans. Ind. Appl. 2018, 54, 1523-1531. [CrossRef]

12. Wang, M.; Huang, Q.; Yu, W.; Huang, A.Q. An isolated bi-directional soft-switched DC-AC converter using wide-band-gap devices with novel carrier-based unipolar modulation technique under synchronous rectification. In Proceedings of the IEEE Applied Power Electronics Conference and Exposition (APEC), Charlotte, NC, USA, 15-19 March 2015; pp. 2317-2324.

13. Varajao, D.; Rui, E.A.; Miranda, L.M.; Lopes, J.A.P.; Weise, N. Control of an isolated sing-phase bidirectional AC-DC matric converter for V2G applications. Electr. Power Syst. Res. 2017, 149, 19-29. [CrossRef]

14. Norrga, S. Experimental study of a soft-switched isolated bidirectional AC-DC converter without auxiliary circuit. IEEE Trans. Power Electron. 2006, 21, 6. [CrossRef]

15. Nakata, Y.; Orikawa, K.; Itoh, J.-I. Several-hundred-kHz single-phase to commercial frequency three-phase matrix converter using Delta-sigma modulation with space vector. In Proceedings of the IEEE Energy Conversion Congress and Exposition (ECCE), Pittsburg, PA, USA, 14-18 September 2014; pp. 571-578.

16. Takaoka, N.; Takahashi, H.; Itoh, J.-I.; Chiang, G.T.; Sugiyama, T.; Sugai, M. Power decoupling method comparison of isolated single-phase matrix converters using center-tapped transformer with PDM. In Proceedings of the IEEE Energy Conversion Congress and Exposition (ECCE), Montreal, QC, Canada, 20-24 September 2015.

17. Chiang, G.T.; Takahide, S.; Masaru, S. Optimal design of a matrix converter with a LC active buffer to onboard vehicle battery charger in single phase grid structure. In Proceedings of the 18th European Conference on Power Electronics and Applications, Karlsruhe, Germany, 5-9 September 2016.

18. He, J.; Li, Y.W. Hybrid voltage and current control approach for DG grid interfacing converters with LCL filters. IEEE Trans. Ind. Electron. 2013, 60, 1797-1809. [CrossRef]

19. She, H.; Lin, H.; He, B.; Wang, X.; Yue, L.; An, X. Implementation of voltage-based commutation in space-vector modulated matrix converter. IEEE Trans. Ind. Electron. 2012, 59, 154-166.

20. Afsharian, J.; Xu, D.; Wu, B.; Gong, B.; Yang, Z. A new PWM and commutation scheme for one phase loss operation of three-phase isolated buck matrix-type rectifier. IEEE Trans. Power Electron. 2018, 33, 9854-9865. [CrossRef]

(C) 2020 by the authors. Licensee MDPI, Basel, Switzerland. This article is an open access article distributed under the terms and conditions of the Creative Commons Attribution (CC BY) license (http://creativecommons.org/licenses/by/4.0/). 